\title{
UC-NRLF
}

|||||||||||||||||||||||||||||||||||||||||||||||||||||||

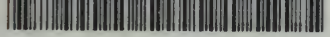

\$B $308 \quad 645$

NOTES ON EQUITATION

AND

HORSE TRAINING 


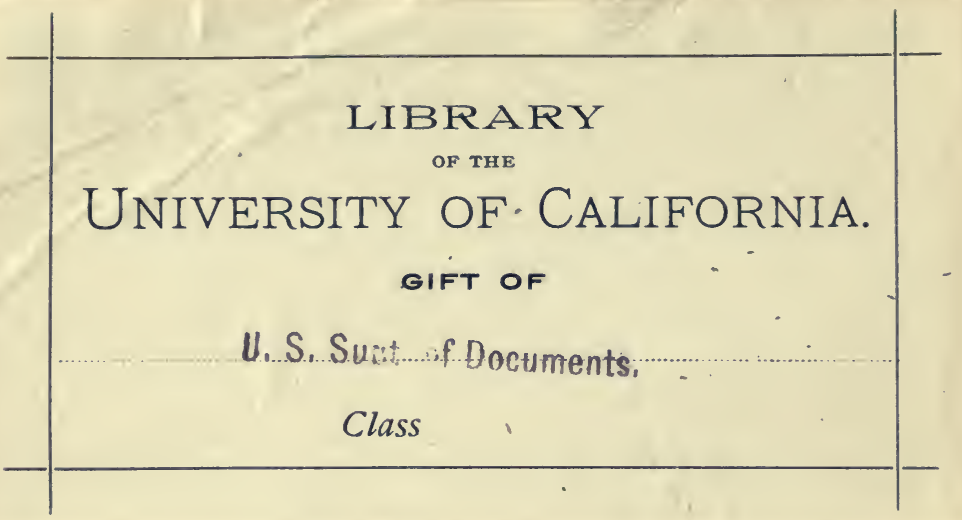





\section{Notes on Equitation and}

\section{Horse Training}

In answer to the examination questions at the School of Application for Cavalry at Saumur, France

Saumur, France. Fécole de l'application de Cavabrie.
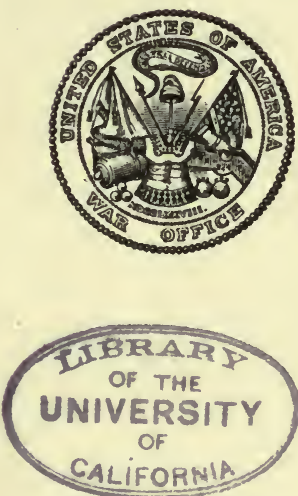

Washington

Government Printing Office

1910 


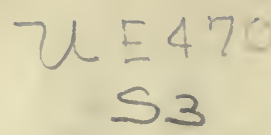

War Departiment,

Document No. 375.

Office of the Chief of Staff. 


\section{War Department, Office of the Chief of Staff, Washington, July 16, 1910.}

Authority having been obtained for the use of the Notes on Equitation and Horse Training, School of Application for Cavalry at Saumur, France, translated by Maj. George H. Cameron, Fourteenth Cavalry, assistant commandant, Mounted Service School, Fort Riley, Kans., and approved by a board of officers convened at the Mounted Service School, they are herewith published for the information of the Regular Army and the Organized Militia.

By order of the Secretary of War:

Wm. H. Carter, Major-General, Acting Chief of Staff. 
Digitized by the Internet Archive in 2008 with funding from Microsoft Corporation 


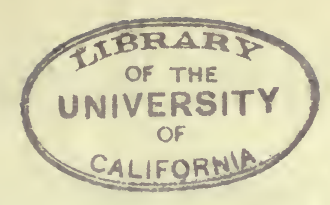

Question I (p. 11):

\section{HISTORY.}

History of equitation.

Antiquity.

Middle ages.

Italian schools.

French schools of the sixteenth, seventeenth, and eighteenth centuries.

Military schools.

Period from. 1789 to 1815 .

Restoration.

Contemporary equitation.

Baucher.

d'Aure.

Name the most noted riding masters in these different schools.

\section{HORSE TRAINING.}

Question II (p. 19):

Definition and object of horse training.

Circumstances affecting duration of training. Condition of the horse, age, breeding; experience and skill of the horseman. Object to be attained.

Three periods of training.

Question III (p. 22):

Preliminary work. Exercise by leading.

Care of young horses. Special recommendations.

Work on the longe; method of giving longe lessons to young horses; its object.

Question IV (p. 25):

Precautions in saddling horses.

Mounting lesson. How should it be given and when? Instructions for men holding the horses.

Precautions with restless horses.

Question V (p. 27):

How should the squad be arranged in the first lesson? In what case should a leader be used?

Necessity for the trot at the beginning of a lesson and the advantages of this gait in early training.

Resistance of young horses. Means of overcoming. 
Question VI (p. 29):

Importance of the movement straight to the front.

To accustom the horse to go straight ahead under the action of the legs. Importance of this lesson. How should it be given? Should it be given often?

Lightness. When should it be exacted?

Principle of constant tension on the reins. Question VII (p. 31):

To halt. How should a young horse be halted?

Should halts be frequent? Advantages and disadvantages, depending upon the horse's balance.

The change of direction. Aids to use.

Question VIII (p. 33):

Outdoor work.

When may it begin?

How should it be combined with work in the hall?

Choice of ground.

Gaits.

Sweats.

Purges.

Condition of the legs.

Appetite and condition of the horse.

Results to be obtained from outdoor work.

Question IX (p. 37):

Suppling the haunches. Accustoming the horse to yield to the effect of one leg.

About on the forehand. With what horses should it be used?

Suppling of the haunches continued.

Haunches in.

Difference between this movement and two-track work.

Dismounted work.

Question X (p. 42):

Suppling the forehand.

Shoulder in. Difference between shoulder in and haunches out.

About on the haunches.

Lateral effect. Diagonal effect.

Question XI (p. 44):

Two-track work. (1) On the track. Haunches in. Haunches out. Disadvantages of these movements at the beginning of training. (2) On the diagonal of the hall. Advantage of this exercise. (3) On a circle.

Two-track work at a slow trot. 
Question XII (p. 47):

Is it advantageous to prolong the first part of training?

Bending lessons on the snaffle bit. When and how?

Easing the hand on the snaffle bit.

Question XIII (p. 49):

How should the gallop be exacted in the first part of training?

The gallop taken by increasing the gait.

Utility of work on a circle.

Question XIV (p. 51):

Backing. Method of execution.

With what horses especially should this movement be practiced?

Work at will.

Condition of the horse at the end of instruction with snaffle bit.

Question XV (p. 54):

Instruction in the double bridle.

Steps to be followed in order to make a young horse accept the curb bit. Different ways of holding the reins.

Bending lessons. General principles. With the snaffle bit. With the snaffle and curb. With the curb bit.

Dismounted bending lessons.

Definitions. In hand. Lightness. The set. The gather. The assemble.

Question XVI (p. 58):

Easing the hand on the curb bit. To what horses should this exercise be given?

What is meant by give and take? Action of the fingers on the reins.

Necessity of often returning to the lesson of going straight ahead.

Lesson with the spurs. When should it be given?

Question XVII (p. 61):

Work at the trot. Rising to the trot.

Necessity of frequentalternating the diagonal pair from which the rise is made. Exception to this rule.

Lengthening and shortening the gait at the walk and the trot. Question XVIII (p. 64):

Work at the slow trot.

Small circles.

Serpentines.

Two track work.

Preparing for the assemble. Halts, half halts, and backing. 
Question XIX (p. 66):

Work at the gallop.

Course to be followed in teaching a horse to lead with a given foot. Question XX (p. 68):

Where should the training of the troop horse stop?

The false gallop.

Taking the gallop alternately from either foot at short intervals.

Change of lead. Precautions.

Continuation of training. Work at the slow trot. Gallop exercises. Question XXI (p. 71):

How are young horses taught to jump?

Jumping at liberty.

Jumping on the longe.

High jumps.

Broad jumps.

Jumping mounted.

Question XXII (p. 74):

To accustom young horses to the saber, to firing, and to noises.

Swimming exercises.

Question XXIII (p. 76):

Various faults of saddle horses. Means of remedying them.

Question XXIV (p. 79):

Conditions to be fulfilled by a good saddle.

How should a horse be saddled?

Question XXV (p. 80):

Holding the snaffle reins.

Holding the double bridle reins.

Handling the reins.

Question XXVI (p. 82):

What is meant by the aids and how are they classified?

Function of the hands. Direct rein. Indirect rein. Rein of opposition.

Question XXVII (p. 84):

Function of the legs; their different effects.

Unison of the legs. Horse in the legs. Horse behind the legs.

Length of stirrups.

Position of the foot in the stirrup.

Question XXVIII (p. 87):

Function of the neck in equitation.

Kind of neck to be selected.

Different positions of the neck.

Different positions of the head.

Influence of conformation. 
Question XXIX (p. 91):

Training for a military race.

First. Amount of work.

Second. Condition of the legs.

Third. Feed during training.

Question XXX (p. 95):

Conditioning a hunter.

Conditioning for endurance races. 



\section{I.}

\section{HISTORY.}

The history of equitation reaches back to remotest antiquity. The horse has always been used in combat, and here we find the origin or, more properly speaking, the cause of the equestrian art. If man had utilized the horse merely to cover long distances or to bear burdens, sufficient training for the purpose would have been an easy matter. But when he decided to fight from the horse's back he was obliged to develop a complete and logical system of steps in training and handling.

Antiquity.-We will not concern ourselves with the manner in which the Greeks, Gauls, and Romans rode. Covering this long period, only the works of Xenophon need be cited; they are especially worthy of mention because they include all the fundamental principles of equitation, and even in our day may be consulted to advantage. It should also be stated that prior to the fifth century a covering stretched over the horse's back was the only form of saddle. The Orientals made slaves bend their backs to serve as mounting blocks, and the Romans made use of stones called "stades," which were set along the roads for the same purpose. It was not until the end of the fifth century that the saddletree was invented, and later stirrups were added. This invention materially modified methods of equitation and permitted the rider to remain longer in the saddle without becoming fatigued.

Middle ages.-During the long period that constitutes the middle ages, two customs contributed largely to prog- 
ress in equitation. These two fashions were chivalry and tournaments. All the youths of the French nobility, eager to rise to the dignity of knighthood, received an education in which the first essential was to learn how to ride. Equitation, it is true, was very limited. The lancer's deep saddle, required to resist an adversary's shock, led to a very constrained seat. Methods of controlling the horse were neither accurate nor progressive; the legs held straight and far out from the horse could be closed only by jerks; the overloaded horses necessarily lacked suppleness. Equitation was simply an exhibition of brute strength, but it was well adapted to the form of combat and to the breed of horses then existing.

During this period of the middle ages we find no works on equitation. The horsemen of that period were certainly not writers and, moreover, equitation with them was a business rather than an art.

Italian schools. - The lack of authors and of historical documents brings us up to the time of Pignatelli, an Italian nobleman, who, in the sixteenth century, founded at Naples the first school of equitation that ever existed. His example was promptly followed in Italy, and other schools were founded, one at Ferrare by Cæsar Fiaschi and one at Naples by Frederick Grison. Their system consisted in exaggerated supplings, exacted in a brutal manner. They obtained results, however, and horses trained in these schools were certainly well in hand, but training was very long and was not always successful. All the horses of Italy, especially those of Naples, had a reputation for viciousness, which was probably due simply to the exceptional severity of the horsemen.

French schools-Sixteenth century.-The principles of the Italian school were brought to France at the end of the sixteenth century by La Broue and Pluvinel, pupils of Pignatelli. The nobility eagerly took up the theoretical study of an art that seemed new to them; competi- 
tions took the place of tourneys, and at the death of Henry II the latter disappeared entirely.

Pluvinel, who was successively first equerry to Henry III and director of the royal stables under Henry. IV, founded the first academies in France.

Equitation as taught in these academies was still slow and restricted. The seat in the high saddle was always straight and stiff. Immoderate use was made of the spur and switch, and the methods of training were based principally on the use of the cavesson and of the posts.

Seventeenth century.- In the seventeenth century the principal riding masters were Solleysel (1617-1680), who published the Parfait Maréchal and translated the works of Newcastle; Du Plessis; De Lavallée; VenDEuIL, who was De la Guérinière's teacher; and GaSPARD SAUNIER (1663-1746), who wrote Treatise on the Complete Knowledge of Horses, The True Principles of Cavalry, and The Art of Cavalry. In England, the Marquis of Newcastle is worthy of mention.

Equitation was still about the same, but they began to work outside the riding hall. Solleysel took up conditioning and published a Method of Preparing Horses to Cover Extraordinary Distances. Gaspard Saunier insists on the necessity of working horses out of doors. He tells us that the best horses of the Versailles school, when put on the road in the campaign of 1691, had great difficulty in becoming accustomed to this new work, and that "they stumbled and seemed to have scarcely enough strength to stand up."

Eighteenth century. - It was not until the eighteenth century that the French school was really and definitely founded, and the honor of establishing it is due to M. de la Guérinière. He was the first to conceive the idea of the natural seat. He had the pommel and cantle of the manège saddle cut down and taught that the rider should seek a firm seat in the balance and uprightness 
of his position. His instruction in equitation was reasonable and natural; he greatly simplified methods of training, and the system that he published may still be consulted with advantage.

Following the riding masters of the eighteenth century, we advance step by step. The Versailles school became celebrated the world over. It was a real academy, which, after laying down the principles of French equitation, sought to maintain these principles and prove their superiority.

Among the numerous riding masters of the eighteenth century should be mentioned La Guérinière, who published The School of Cavalry and the Elements of Cavalry (he died in 1751); De Nestier; De Salvert; De LuberSAC, who trained his horses by riding them eighteen months at a walk; De Montfaucon de Rogles, who, in his Treatise on Equitation, gives some useful information on work with the longe; De Neuilly; Bourgelat, founder of veterinary schools; DU PATY DE Ceam, who published numerous works and was a writer rather than a riding master; D'Auvergne, head riding master at the military school in Paris; Mottin De La Balme, pupil of d'Auvergne, who wrote Essays on Equitation; DE BoHan, who published a Critical Review of the French Army (he thought that equitation should proscribe all artificial gaits); De BoIdefrre, a pupil of d'Auvergne, who wrote Principles of Equitation and of Cavalry; De LA Bigne, and D'A Bzac.

Military schools. - It is important to note that progress in equitation was due not solely to instruction received at the Versailles school, but also to the reforms in cavalry tactics introduced by Frederick the Great. The necessity of having squadrons able to maneuver proved to the King of Prussia that equitation should be the basis of the instruction of the trooper. He built riding halls in all cavalry garrisons and caused the principles of the equestrian art to be taught. 
The example of the Germans was followed by the French cavalry. At the end of Louis XV's reign, the Duke of Choiseul, minister of war, had the King sign a decree, in 1764, creating five cavalry schools-at Douai, Metz, Besancon, La Fleche, and Cambrai. A central school at Paris was to receive the best pupils from the elementary schools after they had passed through a fixed period of instruction. This decree of 1764 was never completely carried out.

In 1770 regimental riding schools were established in nearly all cavalry garrisons. Among these schools the most celebrated were those at St. Germain, Versailles, and Saumur. The one at Saumur, which had been organized in 1763 by the regiment of carbineers, was transformed in 1771 into a cavalry school to which every colonel was directed to send four officers and four noncommissioned officers annually.

Period from 1789 to 1815. - The Revolution suppressed all cavalry schools. However, in 1798, the school at Versailles was reestablished and took the name of National School of Instruction for Mounted Troops. In this new school the instructors did not attempt equitation, but simply endeavored to teach the horse to carry his rider and to travel at marching gaits.

In 1799 two new schools were created, one at Luneville and one at Angers, having the same object and the same organization. The Versailles school was the only one left in 1808, when an imperial decree replaced it by the school at St. Germain, intended to complete the instruction of cavalry second lieutenants after the course at St. Cyr.

Restoration.-Upon the return to power of the Bourbons the Versailles riding school was reestablished and placed under the direction of M. d'Abzac, who was assisted by Messrs. de Goursac and Charrette de Boisfoucaud.

The most noted riding masters of that school were the Viscount O'Hégerty, de Vendière, de Millange, and de Vaugiro. The Versailles school lasted until 1830. 
In 1814 the Restoration suppressed the school at St. Germain and founded a new one at Saumur. The latter was abolished in 1822, following General Berton's conspiracy, and the decree of 1823 established a school of application for cavalry at Versailles.

The Riding School of the Pages, under the direction of O'Hégarty, formed a branch of the Versailles school. But this new organization lasted only a year and on November 11,1824 , the cavalry school was definitely established at Saumur.

Contemporary equitation.-We now come to contemporary equitation, for a long time divided into two schools; a new school, that of Baucher, and the d'Aure school, which continued the methods taught at Versailles.

Baucher.-Little is known of Baucher's antecedents. At the age of 15 he set out for Italy with one of his uncles, who was an instructor in riding schools. He returned to France a few years later and located in Paris. First he gave lessons in a small riding academy in the Rue Montmartre; then he went into a circus in order to popularize his methods. The minister of war had his system tested in the army on two different occasions; one trial was at Saumur. The Baucher system, however, was never officially adopted in the cavalry.

Baucher's methods were entirely different from those taught at the Versailles school. Much more complicated than the Count d'Aure's method, it marked in a way a return to the suppling of the early riding masters. The formula that Baucher often repeated was this: "Destroy the instinctive forces and replace them by transmitted forces." To carry out this programme it was necessary to begin with a series of supplings: "Flexions of the jaw; flexions of the neck, lateral flexions and mobilizing the hind quarters about the shoulders; swinging the fore quarters about the haunches; combination of the play of both extremities or backing." 
All this preliminary work was done in place and resulted in the "gather" (Le ramener); later by the use of so-called "attacks" and "collecting effects," he arrived at the "assemble" (Le rassembler). These first lessons were supplemented by a few movements at the walk, trot, and gallop, and were supposed to complete the training of a horse in two months.

As for the high school, this was Baucher's triumph. $\mathrm{He}$ was an admirable riding master and could make his horses execute the most complicated steps. In one of his works he mentions 16 new riding-school movements which he had added to the repertory of former riding masters.

Baucher wrote several works on equitation. The principal ones are a Dictionary of Equitation and a Method of Equitation Based on New Principles.

D'Aure.-The Count d'Aure, a former pupil of the St. Cyr school, graduated there as a second lieutenant of infantry. He subsequently went into the guard corps and was thus enabled to enter the riding school at Versailles under the direction of the Viscount d'Abzac.

In 1830 he resigned, but, although he gave up the profession of arms, he retained his fondness for equitation, and his brilliant success in that direction led to his being appointed in 1847 to the post of head riding master of the school at Saumur.

His equitation is far from being complicated and studied; it is instinctive, bold, and brilliant. The Count d'Aure was an improvisor who, at the first glance, knew how to secure good results from the most difficult horses. Like all true horsemen, he rode equally. well in the riding hall and in the open; and while he encouraged hunting and racing, he could excel all others at the head of a riding-school exhibition. He directed his efforts particularly to the making of bold and energetic horsemen and

$53521^{\circ}-10-2$ 
always preached the movement to the front: "Push, push up to the bit," was the excellent precept that he continually repeated to his pupils.

Count d'Aure wrote two works on equitation, one in 1830 and one in 1853, and during the eight years from 1847 to 1855 was head riding master of the cavalry school. 


\section{II. \\ HORSE TRAINING.}

Definition and object of horse training.-By horse training is meant a series of exercises that render the horse obedient, while preserving and developing his inherent qualities. Its object is not, therefore, to simply master and control the instincts of the animal; it must also subject him to a muscular training that, by suppling, will strengthen all parts of the body. As a result his gaits will be perceptibly developed by the very harmony of his movements and by the exact distribution of his weight produced under the influence of the aids.

Circumstances affecting duration of training.-The length and value of the service that a horse can render depend in great measure upon the manner in which he has been trained. A colt should be called upon for only such exercise or work as is reasonable, considering his age, strength, and ability. To exact anything beyond his capabilities is to set up resistance and to inevitably bring on injuries and early condemnation.

The breeding of a horse (thoroughbred or underbred), the nature of his feed, and the amount of work he has been equal to in the hands of his breeder are considerations that will allow us to fix upon the date, more or less distant, when he should be fit for service. Training when once begun must be regulated by these same considerations. It is self-evident that a horse kept on grass until he is 4 years old needs more nursing than the pure-bred horse that is raised almost from birth on oats.

It is also obvious that conditions of training will differ widely according to the skill of the person in charge. An 
expert horseman will finish the work more satisfactorily and more quickly, and his composure and experience will enable him to mount without trouble a younger horse, because, in his hands, there will be none of those struggles that produce blemished animals.

Finally, the time required for training will vary according to the object to be attained. Many long months are often necessary to work a young horse up to high-school exercises, whereas, occasionally, a few weeks will be sufficient to produce a horse free at the three gaits and galloping with either lead.

Three periods of training.-The training of a young horse may be divided into three periods-preliminary work, work in the snaffle bridle, work in the double bridle.

(1) Preliminary work.-In this first period the horse is gentled. He is taught to allow himself to be saddled and mounted, to go straight ahead at the walk and trot, to turn to the right and to the left.

Work on the longe should properly be taken up in the preliminary period.

Under certain circumstances and with certain horses outside work may be begun.

(2) Work in the snaffle bridle.-The horse is first brought to a thorough understanding of the effects of the legs. He is next taught to obey the simple effects of the snaffle.

At the end of this period the horse should understand work at the three gaits on the three lines; ${ }^{a}$ he should know how to take the gallop with either lead, and how to work on two tracks ${ }^{b}$ at the walk and at the trot.

In this second period outside work will have been continued or begun.

a The straight line, the diagonal, and the circle.-Translator.

$b$ Where the fore and hind feet do not follow the same track, e. g., in passaging.-Translator. 
(3) Work in the double bridle, which may be subdivided into two parts:

(a) All work with the snaffle is repeated with the double bridle. Instruction is completed as regards the upper aids. $^{a}$ The horse is confirmed in his work at the gallop and finally is taught the change of lead. Here is where ordinary training stops; training sufficient for the horse of the trooper.

(b) Preparatory period for high-school work in which the obedience of the horse is further developed by a system of exercises that increase his suppleness and strength. He acquires cadence in gaits and becomes light, or, more precisely speaking, balanced.

High-school work might be considered as a fourth period, and the animal would then be taught the different manners and steps of which this school is composed, such as the high trot, in place and gaining ground, and the change of lead with each stride. 


\section{III.}

Preliminary work-Exercise by leading.-When young horses, sent from remount depots or by purchasing boards, arrive at the station, the squadron commander should place them all together in the best stable of the squadron, turn them over to troopers known to be fond of horses and make sure that all precautionary and hygienic measures are taken to gradually accustom them to changed conditions and to handling by men.

Young horses should be exercised daily; at first by men on foot and later led beside kind old horses. This exercise, which is at a walk, is of great advantage not only to strengthen the animals but to quiet them by making them familiar with outside objects. The only drawback is that, ordinarily, the mistake is made of invariably leading the horses on the same side. They eventually acquire a false set of the neck which could be easily avoided by holding them for a time on the left as well as on the right.

Care of young horses.-After each exercise, the legs are rubbed and the tendons massaged. Following a wash down with plenty of water, the application of flannel bandages produces highly beneficial results to the fetlocks and tendons; the bandages retain the heat, help circulation, support the tendons, prevent windpuffs and swellings. Put on in the stable, they should encircle the fetlock and the lower half of the cannon. They must not be too tight; the fastening tapes in particular should be somewhat loose. It is useless to leave flannel bandages on the legs all the time; the important thing is to put them 
on after exercise; during the five or six hours following hard work they are especially efficacious.

In addition to the precautions generally adopted, it is well to see that the blanket strap or surcingle is fastened around the place where the saddle girth belongs and not pushed forward to the horse's elbows; the object being to prevent the formation of two worn places.

Work on the longe.-This work may be of great service in horse training, provided, however, that the longe is used as a means of training and not as a medium for fatiguing exercise.

The following principles must dominate in this work:

(1) The horse is to be controlled by the longe and not by the whip; the only function of the latter is to move the horse forward.

(2) The length of the longe is to be frequently changed. The horse should alternately stretch himself on a large circle and bend bimself on a small circle.

(3) The gaits should be frequently changed and the horse brought to the walk from time to time in order to avoid the stiffness of gait that would result from prolonged work.

The progressive method of handling a horse on the longe is given in the regulations (United States Cavalry, paragraph 350) and is described in detail in several works; there is, therefore, no necessity of repeating details here. It will be sufficient to point out the different cases in which the longe can be used to advantage.

Work on the longe can be used:

(1) To exercise young horses without injury and without fatigue to the joints.

(2) To give first lessons to horses difficult to manage.

(3) For horses that hold back or fight.

(4) For horses with one shoulder more developed than the other. 
(5) For those that will not work equally well on either hand.

(6) For horses that bend themselves with difficulty.

(7) After horses have acquired the habit of this work, lessons in jumping on the longe can be given later without difficulty; horses should not be put at the jump until they are thoroughly manageable with the cavesson and longe. 


\section{IV.}

Precautions in saddling.-In order to accustom young horses to their equipment, they should be saddled during the period when they are exercised by leading. The saddle is put on without stirrups or stirrup straps; it must not be placed too far back, and, on leaving the stable, the girth should be tightened only slightly. The girths are readjusted during the exercise.

With nervous horses, it will be well to use the longe to quiet them by a little work before placing the saddle on the back.

After the horses have become accustomed to the saddle and the girth, the stirrups should be replaced and allowed to hang down on each side during several exercises. In this manner the horse will be perfectly prepared for the lesson in mounting which becomes that much more simple; early resistance frequently results from both saddling and mounting a horse for the first time on the same day.

Mounting lesson.-At first the trooper should get into the saddle as skillfully as possible without any attempt to mount by the numbers, and especially without being in any way exacting.

The lesson should be given after the horse has been worked for some time or at the end of his work. An assistant stands facing each horse.

The trooper approaches the horse's head, caresses him on the forehead, on the eyes, the neck, and the haunches. He slaps the saddle, pulls the stirrups out and lets them drop back; he then grasps the reins, leaving them very long. He mounts the horse without hurry, but also without hesitation. 
If, during the lesson, the horse backs or moves away, the trooper returns to the animal's head, leads him up a step or two with the snaffle reins, and gently begins the lesson anew.

After seating himself in the saddle, the trooper should use his right hand to assist in engaging the off stirrup. By feeling for the stirrup with the toe there is danger of frightening the horse by touching him unintentionally with the leg or stirrup.

Restless animals. - The assistants should stand squarely in front of the horses and not on the off side. Their business is to simply caress the animal's head without holding the reins.

With horses that are hard to mount, the cavesson should be used, the longe held by an experienced and skillful man.

Mounting lessons should be given on the off side as well as on the near side and should be repeated daily until the horse stands absolutely quiet. The (individual) lesson, however, should not be prolonged, for the horse will have greater tendency to become restless the more he is held in one place. 
V.

Arrangement of the squad for the first lesson (in mounted work). - If a riding hall is available, horses should be worked from the beginning without regard to distances. The troopers are more at ease when they need not concern themselves about distances - often hard to keep with horses of very uneven gaits. Moreover, it is a bad plan to always group young horses, as they thus acquire the habit of "sticking in ranks." If, from the start, it is necessary to work on the road, a couple of perfectly sure old horses must be placed at the head of the young ones in order to set them an example in quiet behavior and free movement.

Necessity of using the trot at the beginning of a lesson.-There are several advantages in using the trot to begin work:

(1) It starts the horses going straight ahead and brings them in hand; busy at the trot, they have less idea of resisting.

(2) It expends the surplus vigor (takes the edge off) of young horses, and they become more quiet and attentive.

(3) This gait must be considered as the best of supplying exercises. In his book on equitation, La Guérinière has a chapter entitled "The necessity of the trot and the utility of the walk." In this chapter he says:

By the trot, the most natural of the gaits, a horse is made light on the hand without spoiling his mouth, and his legs are stretched without straining them, because in this action, which is the highest of all natural gaits, the weight of the horse is borne equally by two legs, one front and one hind; as a result the two others are easily raised, sustained in the air, and stretched to the front, thus giving a first stage 
of suppling to all parts of the body. The trot, therefore, without controversy, is the foundation of all lessons to make a horse obedient and clever.

Resistance of young horses.-The instructor must forbid any punishment in the first lessons, because it often happens that when a horse frets it is only on account of timidity or of high spirits or of ignorance.

To prevent struggles, it is well to have available during the first lesson several dismounted men, ready to take by the head the most unruly horses, as well as those whose riders are in trouble. 
VI.

Importance of the straight ahead movement.-Above everything else the horse must go freely straight ahead. The lesson with this object in view must be the first of all lessons; from the beginning of horse training the horse must be accustomed to yield to the action of both legs. This is essentially a sign of docility; the full or the limited obedience of the horse shown in this first test will be an indication of a brief or a protracted period of training.

To accustom the horse to go straight ahead under the action of the legs.-The leg lesson is admittedly the most important lesson, and there is good reason to return to it during the whole period of training. For the first occasion observe the following rules:

Never keep the lower leg glued to the horse's flank, but use repeated taps with the calves.

Tap the horse near the girth and do not reach too far back.

Begin by giving the lesson when passing from the walk to the trot, next when lengthening the trot, and finally when passing from the halt to the trot.

Anticipate and assist the action of the legs by clucking with the tongue or by the use of light taps with the whip.

These rules are especially applicable to riding-hall lessons, for in outside work on a road young horses have a natural tendency to go straight ahead, following the old horses at the head of the squad.

Lightness - When to be exacted.-A horse is light when he obeys easily and promptly the indications of the rider. This is not a question merely of flexibility of jaw and suppleness of neck, but rather of balance, and in our opinion 
the degree of lightness corresponds to the more or less finished balance.

Therefore in the first lesson there should be no anxiety about lightness, for, as we have just remarked, it will be a natural result of training. If a horse is not easily controlled by the legs, is not well suppled in the shoulders, and does not know how to properly employ his haunches he can not be really light.

Not until later can perfect balance (or lightness, if you please) be obtained and then only by coordinating the different results of training.

The principle of constant tension on the reins.-Although the instructor during the first weeks of training need not concern himself with the lightness of the horse, he must urge the troopers to keep a constant light tension (feel) on the reins. At first the trooper must do the work-that is, must tighten the reins-but later the horse itself, having become accustomed to the pressure of the bit and having always present the idea of going straight ahead, will, of its own accord, keep the reins taut.

It is important to distinguish between pulling on the reins and the principle of keeping a constant tension on the reins. A hand too rigidly fixed, with fingers too firmly clasped, will oppose the free play of the neck and will be contrary to the principle just stated. Therefore in the leg lesson, when forcing the horse straight ahead, the hand must not oppose the stretching of the neck; on the contrary, the fingers should be slightly opened up so that nothing can clash with the animal's intention to obey the aids. 


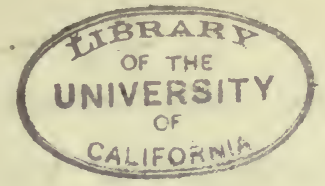

VII.

The halt-How to halt a young horse.-To halt, lean back slightly and pull on the reins with gradually increasing force, in order to slow and then stop movement.

When the trooper pulls on the reins the horse should neither raise nor lower the head. The muzzle should remain to the front and the whole mass of the neck should flow back toward the withers. In other words, under the action of the reins the horse should neither throw his nose up in the air nor bring it down against his chest, closing up on the hand. This latter fault is particularly to be avoided. It is more difficult to raise the muzzle than to lower it, and any horse that at the beginning of training withdraws from neck control becomes especially difficult to instruct.

Should halts be frequent?-The halt should not be frequently practiced on horses inclined to fret nor on those with nind legs set under and thus liable to sit down on the haunches. On the contrary, it should be often used in cases where the conformation throws too much weight on the shoulders. Training is nothing more than the quest of balance, and the halt will be a well-chosen suppling exercise for a horse with a high, powerful croup that makes him difficult to slow up.

The change of direction-Aids to use.-To change direction to the right, open gently the right rein by carrying the wrist to the front and right, without moving the elbow and without twisting the hand.

The effect of opening must be produced laterally and as little as possible from front to rear. It induces a movement of the haunches and furnishes, therefore, a prelimi- 
nary means of accustoming the horse to yield to the pressure of one leg.

To change direction to the right, then, the aids to be used are the right rein and the right leg. ${ }^{a}$

In the first lesson the turning movement will not be executed with precision, but this is of small importance.

It is not a question of bending the horse on a quarter circle as should be done with a trained horse; all that is necessary is to make the horse understand what action results from the opening of one rein and the closing of one leg.

$a$ When the leg and rein on the same side are used as aids, they are called lateral aids; thus, also, lateral effects and lateral equitation.The Board. 


\section{VIII.}

Outdoor work.-Conditioning is not a chapter apart in the education of the young horse; conditioning and training run together and the horse acquires at the same time habits of work and of obedience. It would be a mistake to think that the conditioning of a horse requires the jockey seat on a sanded track. Riding-hall work and outdoor exercise are generally sufficient.

When to begin.-Outside work should be begun as early as possible. It is an advantage to take the horses out as soon as they know how to go straight ahead and to turn to the right and left. Outdoor rides, intelligently conducted, "put horses into the bridle" $a$ and improve the carriage.

Moreover, this is a good way to quiet the animals as troopers are less exacting on the road than on the ridinghall track.

Combination of riding hall and outside work.-This outside work must be combined with the lessons in the hall. There is no necessity of feeling compelled to follow blindly a set schedule such as to work on the road for six weeks and then stay inside for several months. On the contrary, it is of distinct advantage to alternate the two and to have at least two outdoor rides each week. However, the officer in charge of training must base his de-

$a$ To put a young horse into his bridle is to make him take hold of his bit and bear on it properly whenever he moves forward under the impulse of both legs. He thus, as previously stated, produces a proper tension on the reins. If a horse fails to bear on the bit and to tighten the reins when the legs urge him forward he is said to be "behind the bit."-The Board. 
cision as to schedule upon the deportment, conformation, and general condition of his horses. Horses in poor condition, those that fret and that throw too much weight upon the hind quarters should be taken out frequently. Clumsy horses and those that throw the weight on the forehand should receive most of their work in the hall.

Choice of ground.-If possible, soft ground should be selected. On hard ground the fetlock joints become fatigued and the lower legs are liable to injury; the horse develops windpuffs and splints. But it would be wrong to work over heavy ground; the hocks would suffer and eventually spavins would appear.

When training has been completed, good results may be obtained by riding a horse with loose reins over bad roads. This forces the horse to take the initiative and as he is allowed complete freedom of the head, he easily gets out of difficulties even on very bad ground.

Gaits.-In outdoor rides there should be alternation of the walk and trot, gradually increasing at each outing the amount of time devoted to the trot. Toward the end of the period of training the distances at a trot should be lengthened; but there should always be intervals of at least ten minutes at a walk to allow the horse to resume his normal breathing.

The gallop should not be used in outdoor work except upon very good ground. If you have available only bad or fair footing, do not gallop. By rigidly enforcing a schedule, regardless of conditions, the result will inevitably be injury to the animals. In any case, galloping should not begin outside until the rider is sure of his ability to make his horse lead off freely with either foot. He can then work his mount equally on both sides and can avoid those struggles that put a horse in the air during the whole ride.

Sweats.-A horse should not be sweated at the beginning of training, at least not until his disposition has been 
studied. As a rule any excess of fat disappears with ordinary work.

When giving a sweat, a suitable day and hour should be selected; the horse should be well covered, wrapping especially the parts where there is most fat; work the horse a little at a walk and then gallop him steadily until he is in profuse perspiration; do not hurry about scraping, but let the sweat have plenty of time to exude; uncover the horse little by little and scrape slowly, bearing well on the edge of the scraper to force out the sweat; reblanket the horse and lead him around at a walk for a few minutes; uncover and scrape again; finally walk the horse until he is perfectly dry before returning him to the stable.

There should always be an interval of about five days between sweats and ordinarily three or four will be sufficient. Be careful that the horse does not drink to excess at the next watering.

The first sweat is hard to bring; the third and fourth time it comes more easily.

Purges.-In addition to sweating, it is sometimes of advantage to administer purgatives to reduce the intestines of horses with too much belly.

Before purging, a horse should be put on diet and mashes for forty-eight hours. Either aloes or sulphate of soda may be used as a purgative. Aloes acts directly upon the large intestines and for this reason it is used by preference for taking off belly. It is administered as a ball in doses of 30 to 50 grams ( $7 \frac{3}{4}$ to $12 \frac{3}{4}$ drams). ${ }^{a}$

Sulphate of soda (Glauber or horse salts) is given dissolved in the drinking water and has the great advantage

$a$ In our service a ball is usually made of aloes, 6 to 8 drams-with ginger, 1 dram; or the issue "purgative capsule" is used. Glauber salts is an excellent laxative but is not on our supply table. The use of physics to reduce fat has been abandoned in this country on account of the accompanying weakening effects, but dieting is always enforced.The Board. 
of never irritating the intestines. It must be given in

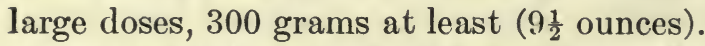

Condition of the legs.-Overexertion of the legs manifests itself in splints, wind puffs, spavins, and in the swelling and stiffening of the fetlock joints.

In case of swelling of the fetlocks and wind puffs, avoid work on hard ground, and cut down the work; use douches and hand rubbing and apply flannel bandages.

For splints, use red ointment (mercuric ointment-a blister) as soon as the injury appears.

For bog spavins stop work in the hall and all collected work at the gallop; exercise quietly on the road and use douches.

Appetite and condition of the horse.-A young horse must be given substantial nourishment in order to readily resist the first fatigues of training and also because he is still growing at the age when his education is undertaken. More or less hay, according to the animal's condition, and always plenty of oats. From time to time, every eight or ten days, a handful of sulphate of soda can be given in the drinking water or in a mash to counteract the heating effect produced by oats.

If horses are too fat, cut down the hay and also the water. If the horses are in poor condition, give linseed mashes and put dry bran in the oats; try beans and carrots; in a word-variety. Frequently a horse refuses to eat because he has been put on full oats too suddenly; in this case, cut down the ration or even place the animal on diet for a time.

Results.-In conclusion, if outdoor work has been alternated with riding-hall work in proper ratio, the young horse, at the end of training, has lost any surplus fat; has acquired muscle; his joints and tendons have been strengthened and his wind developed. In short, after a length of time which varies with age, breeding, and disposition, the horse is in condition to undergo without injury the hardships of the service for which he is destined. 
IX.

Second leg lesson or first suppling of the haunches.We have already given the horse the first leg lesson-the lesson in moving straight to the front-by drilling him to yield to the action of the legs. We will now teach him to yield to the effect of one leg, carrying the haunches to the right or left; this second lesson, which necessitates the crossing of the hind legs and gives mobility to the hind quarters, is a most useful suppling for the horse.

The best way to give a horse this second lesson is to use half turns on the forehand in reverse; half turns on the forehand are nothing more nor less than abouts on the forehand made while marching. ${ }^{a}$ For example, marching. on the right hand, leave the track on a diagonal (oblique) and return to it by a half turn to the left ${ }^{b}$ exacted by a

$a$ In the expressions "demi-voltes renversés" and "demi-tours sur les épaules faits en marchant," an apparent inconsistency is encountered. The "demi-tour sur les épaules" is the "about on the forehand" of our drill regulations. If, however, instead of being held stationary, the forehand is allowed to gain ground (en muarchant), we will have the movement contemplated in the lesson, but it will necessarily be on two tracks, the semicircle made by the hind feet having a greater radius than that made by the fore feet. Now, the "volte" is nothing more than our individual "circle," and is a one-track movement. For clearness, then, it is evident that a word is needed to accurately describe this "about made while marching," and the board has decided to use the expression "half-turn." The "turn" of the riding hall will be a movement of $360^{\circ}$ and it may be urged that the command will clash with the $90^{\circ}$ turn of the drill regulations; but, as one is for an exercise by the individual trooper and the other is for a change of front by a body of men in line, it is thought that no confusion will result.-The Board.

$b$ The commands for this exercise are: (1) Right oblique, (2) MarcH, and (1) On forehand, (2) Half turn in reverse, (3) MARCH.

"Half turn in reverse" could, in this case, be expressed "Left half turn," but "in reverse" (renversé) has particular significance and the terms should be retained on that account. 
very pronounced action of the left leg and left rein. This strongly marked lateral effect carries the horse's haunches to the right; that is to say, the horse while still gaining ground yields to the effect of the left leg (and left rein) and thus describes a half turn. The same movement is executed while marching on the left hand and the horse eventually swings the haunches easily about the forehand, without halting, without striking the fetlocks, and without dancing. (Without either increase or decrease of cadence.)-The Board.

We have specified half turns reversed, but abouts, full turns, and later, serpentines can also be used.

About on the forehand.-The second lesson may also be given by means of the abouts on the forehand; but it would be wise not to insist upon this movement and to use it only when absolutely necessary.

The great drawback to abouts on the forehand is the frequent halting of a young horse and the holding of him in place by the action of the legs. This lesson used repeatedly at the beginning of training will eventually check any movement straight to the front that has been already obtained.

Major Dutilh, although he explains in detail the system of abouts on the forehand, himself points out the danger of using them, for, following his explanation, he says:

Caution riders that abouts on the forehand have the disadvantage of rendering horses unresponsive to the action of the legs. In order to

It must be remembered that at this stage of his instruction the colt has learned little and would be unable to execute a left half turn in the open. In the hall, however, he understands the opening of the right rein that guides him off the track, to which he has grown accustomed, into the right oblique, and he understands the opening of the reverse rein to guide him back. The prompt and forceful use of the left leg then swings his haunches about and instead of being confused he moves out willingly in the opposite direction, because he is again on his familiar track next to the wall.-The Board.

Obliquing to the right, if the command be simply: (1) On forehand, (2) Half turn, (3) March, the movement is continued to the right in the turn. 
counteract this tendency, which promptly leads up to resistance, it is urged that the horse be pushed straight ahead at a trot after each one of these pivotings.

In spite of these drawbacks, the abouts on the forehand can be employed advantageously in certain cases. In fact, they should be used with horses that are too hotheaded, with those that bulge on the hand, and with those that are slow to learn. $* * *$

(The different series of exercises in the Dutilh method of executing the abouts on the forehand are omitted as a refinement for which there is rarely sufficient time.The Board.)

Suppling of the haunches continued.-If the preceding lessons have produced mobility of the croup by lateral effects, and if the horse yields readily to the action of the leg and rein on the same side while marching on an arc, it is time to exact the same obedience while marching on a straight line or following the track, that is to say, to start the horse on the movement called "haunches in." This movement, which continues the suppling of the croup, has the further advantage of confirming obedience to the legs.

Haunches in.-Marching on the right hand, indicate opposition with the left rein and close, at the same time, the left leg. If the horse yields and swings the croup inside of the track by even one step, while still gaining ground to the front, straighten him again at once with the right rein and leg; repeat this swinging of the haunches several times, but in the first lessons, do not insist. Gradually lengthen the time before straightening.

* $\quad * \quad *$ * * * *

Haunches in, is a suppling exercise for the hind quarters; its object is to make the spinal column pliable and to accustom the hind legs to stepping across each other. It also makes the haunches quick to obey and constitutes an excellent preparation for two-track work and for the gallop lead. 
Difference between haunches in and two-track work. The movement of swinging the haunches in must not be confused with two-track work. The latter is a regular movement to be taken up after the completion of the suppling of the forehand as well as that of the haunches; in this movement the horse, placed or held correctly in a position from head to croup, is oblique to his path rather than curved to it. The former, on the contrary, is merely an exercise with the object of making the haunches supple and easily eontrolled.

Dismounted work.-Before beginning mounted work on the haunches, it is sometimes useful to pave the way by dismounted work with the whip; such work may be advantageously combined with longeing. Work with the whip is directed especially at the hind quarters and should not be confused with the dismounted bending lessons which we will take up later in curb-bridle work.

There are two principal movements:

(1) To move the horse to the front with the whip.-The horse being on the track and on the left hand, seize the reins about 6 inches from the bit with the left hand, pull them forward and at the same time strike light taps with the whip behind the girth where the leg is usually applied.

If the horse moves forward, let him walk a few steps, make much of him, and then halt him.

If he stands still, gradually increase the force of the whip taps until he moves.

If the horse backs away, hold him tight with the hand on the reins and continue the use of the whip behind the girth until he moves forward; then caress him and halt him.

(2) To swing the haunches.-The trooper standing on the left of the horse seizes the reins with the left hand and applies light taps with the whip behind the girth until the horse moves the haunches from left to right. 
The left hand prevents the horse from getting away to the front and by opposing the forehand to the haunches, assists the action of the whip in moving the hind quarters.

In this movement the forehand should move and the fore legs should cross, but on an arc of very small radius.

Dismounted work should be considered as of only secondary importance. It will be of great benefit with some horses and practically useless with others. In any case, dismounted lessons should always be very brief. 


\section{$\mathrm{X}$.}

Suppling the forehand.-The hind quarters having been drilled by the foregoing work, we must promptly train the forehand in order that both ends of the horse shall be in harmony as regards mobility and suppleness.

Shoulder in.- "Shoulder in" is the starting point in forehand suppling; this exercise furnishes the means of bending the forehand and spinal column and of training the forelegs to cross each other easily. La Guérinière says:

This lesson produces so many good results at once, that I consider it the first and the last to be given to the horse.

"Shoulder in" is obtained in the following manner:

Marching on the right hand, open the right rein as in changing direction to the right, and press the left rein upon the neck. Close the right leg to push the mass from right to left and slip the left leg behind the girth to restrict as much as possible the swinging of the haunches.

The support of the left rein is indispensable in order to keep the proper balance of the shoulders-that is, to prevent the weight of the right shoulder from plunging heavily upon the left shoulder.

The horse's head must be firmly held between the two reins, otherwise the exercise would become a lateral flexion of the neck and would do more harm than good.

The bending of the horse's body should not be overstrained. For example, it is perfect if, on the right hand, the left front foot and the right hind foot make tracks on a line obviously parallel to the wall of the riding hall. 
The difference between shoulder in and two-track work is analogous to that between haunches in and twotrack work. In the movement of shoulder in, if the trooper eases the hands slightly, the horse, being bent and not obliqued, will quit the track and start to make a circle. If, in haunches out on two tracks, the trooper eases the hands, the horse, being traversed and not bent, quits the track and moves off at an oblique.

About on the haunches.-The about on the haunches consists in causing the forehand to describe a half circle around the haunches. It is a difficult movement and, customary methods of instruction to the contrary notwithstanding, should not be taken up until after the completion of the exercises of haunches in and shoulder in.

The first part of the movement is easy enough, but the last part is difficult. Take for instance the right about. Begin the movement like a change of direction to the right, holding the haunches firmly with the left leg. In the remainder of the exercise the controlling aids are the left rein and the left leg. The left rein has first a bearing effect that, assisted by the right rein, swings the forehand on its path; thereafter, it has an effect of diagonal traction, pulling the mass back upon the right hock and thus holding the haunches stationary.

The about on the haunches is executed on the inside hind leg, the outside hind leg gaining ground around it.

Lateral effect and diagonal effect.-The movements that have been already executed with the rein and the leg on the same side suffice to show the difference between the lateral effect and the diagonal effect.

It is easy to see that the former is the means and that the latter is the end in view. With young horses the right rein comes to the assistance of the right leglateral effect. With trained horses the rein places or controls the forehand while the leg controls the haunchesdiagonal effect. 


\section{XI.}

Two track work.- - Two track work consists in making the fore legs cross each other and the hind legs cross each other, gaining ground to the front or without gaining ground to the front; the horse is set (placed) to the flank toward which he is marching.

(1) On the track-Haunches in.-When both the forehand and the haunches have been sufficiently suppled, the movement of "Haunches in" should be changed into "Haunches in on two tracks." a That is to say, that as the horse gradually becomes more obedient to the leg, the lateral effect should gradually make way for the diagonal effect. In other words, when the horse yields readily to the left leg, for instance, it is useless to continue the left rein in opposition, and we accordingly attain the full and regular movement in which the forehand is set in the direction of march.

Haunches out.-After the horse has mastered the preceding movement, he should be taught haunches out on two tracks. ${ }^{a}$ The principles are the same; but this latter lesson is much to be preferred, because the horse executes it without being guided by the wall or by routine; he merely obeys the reins and legs.

In this movement the horse must not be allowed to hang back or to get behind the bit. To keep him well into the reins, the two track lesson must frequently be terminated by moving out either on a half turn in reverse or on an oblique to change hands.

a"On two tracks" will be a general preparatory command. Thus: (1) On two tracks; (2) Haunches in (or out); (3) МавсH. (1) On two tracks; (2) Right (or Left) oblique; (3) MaRcH.-The Board. 
Two track movements with the haunches in or out are very fatiguing to the young horse and should not be prolonged beyond a few steps. Undue persistence in these movements would make a horse refuse; he would strike his fetlocks while stepping across and would sooner or later resist in order to escape the pain caused by these repeated blows.

(2) On the diagonal of the hall-Advantage of this exercise.-Movements of the haunches should be repeated on the diagonal of the hall (while changing hands) and in half turns. Two track work on the diagonal of the hall makes a perfect lesson. Any tendency to slacken the gait is avoided, and the horse takes to this exercise more willingly than to that on the track because it is easier and there is less chance of striking the fetlocks in cross stepping.

In two track work, do not persist in a movement poorly begun or poorly executed. If the horse frets, dances, or backs, put him on a straight line again, quiet him, and then return to the two track lesson.

(3) On a circle.-Two track work on a circle ${ }^{a}$ is executed on the same principles. The following remarks are pertinent:

(a) Haunches out on two tracks on a circle puts the horse into his bridle and upon his forehand. He supports himself to a great extent on the forelegs and lightens the hind quarters which, having a longer route to travel, derive more benefit.

This movement should be used for horses that hang back, or that have too much weight on the hind quarters.

(b) Haunches in, on two tracks on a circle produces effects diametrically opposite. It is a special exercise for suppling the forehand and should be used for horses that have too much weight on the shoulders.

a After a platoon or squad has been placed upon a circle as prescribed in paragraph 241, Cavalry Drill Regulations, the instructor commands: (1) On two tracks; (2) Haunches in (or out); (3) MarCH. 
Two track work at a slow trot.-All two track exercises should be repeated at a slow trot. Such work, with the haunches set diagonally, develops rapid progress in young horses. ${ }^{a}$

$a$ After the young horses have been sufficiently trained to execute two track movements for several steps and the instructor desires to have such movements discontinued simultaneously, he commands: "As you were." In order to study the progress and faults of the individual horse and rider the instructor causes members of the squad to execute in succession a given movement by the use of the preliminary command: First trooper. Thus, with the squad marching on the diagonal of the hall the instructor commands: (1) First trooper; (2) Haunches right, in time to add (3) MARCH, when the leading trooper is at about 6 yards from the track. Each trooper in succession executes the movement on the same ground and the instructor places himself where he can closely observe details. 


\section{XII.}

Is it advantageous to prolong the first part of training?-There is a distinct advantage in prolonging the part of training that is done on the snaffle bit. So long as the young horse is unsteady and wabbly, so long as there is danger of encountering resistance, it would be better to leave him on the snaffle. With this bit struggles are less frequent, those that are unavoidable are less harmful, and on the days of bad humor on the part of horse or rider there is less chance of ruining the work accomplished in preceding lessons.

Moreover, the young horse nearly always needs to have his neck raised, strengthened, and set. If he has no breeding and the curb bit is used too soon, he has a tendency to bring the muzzle down against the chest or to bear heavily on the hand. If, on the contrary, he has class and energy, and is put on the curb bit before he thoroughly understands the leg aids, he will struggle against the hand, use his strength in fighting the bit, and subsequently much time will be required to quiet him and smooth out his gaits.

Bending lessons on the snaffle-When and how to be exacted.-It is better to take up bending lessons on the snaffle too late rather than too soon. As long as the horse is not well up in the reins, there is no opportunity to begin. When he bears properly on the bit, and not before, he should be taught to yield the jaw and to place the head to the right or left.

In preliminary bending lessons, to draw the head to the right the rider pulls gently and slowly upon the right rein and holds the left rein steady to regulate the amount of 
displacement of the head as well as to prevent, as far as possible, any bending of the neck; the head alone should be turned to the right. The movement will be well executed if the head, held high rather than low, remains vertical; if the jaw is flexible, and if the displacement of the head to the right or left does not pass outside of the vertical planes parallel to the axis of the horse and passing through the points of the shoulders.

In these bending lessons, which are invariably practiced while the animal is moving, the legs must be used to keep up a steady gait and to prevent slowing up.

Easing the hand on the snaffle.-Bending lessons should always be followed by easing the hand, which is a rest for the horse after a somewhat fatiguing exercise, and a relief to the hind quarters; this exercise is also a means of extending and lowering the head of the horse and of accustoming him to keep in touch with his bit.

When the easing of the hand is well done, the horse, after yielding the jaw, should extend his neck little by little and answer to the bending lesson even after his head is down. These bendings at the end of the reins give most excellent results.

The easing of the hand should be most carefully distinguished from the movement when the horse bores savagely against the hand. This habit of boring or diving is easily acquired if the rider releases his hand suddenly instead of keeping a constant tension on the reins and gradually following the horse's head. 


\section{XIII.}

When and how should the gallop be exacted in the first part of horse training?-Almost invariably the gallop lesson should be begun early. There is then available an additional means of suppling the horse, of strengthening him, extending him, and pushing him straight ahead. But a fixed rule can not be laid down with horses and especially in this matter; the time to take up first work at a gallop depends upon the conformation of the horse, his condition, his leg development, and the kind of ground available. It would be stupidity to gallop frequently on a colt that drags his legs and is disunited at a trot and that has difficulty in holding up the part essential to training. On the other hand it is proper to gallop repeatedly on a vigorous horse that has been worked before purchase, on the horse with good strong legs, and particularly after he has been thoroughly confirmed in the correct trot.

This is a matter of common sense and experience; a horseman will promptly decide at what moment he can profitably begin gallop work with the horse he is riding or with the squad he is instructing.

The gallop by increase of gait-Utility of work on a circle.-Passing from the walk to the gallop may be considered as a test of advanced training; it will therefore be entirely out of place at this stage, and we must take up the gallop only by increasing the gait from the trot. Moreover, it is essential that the horse shall work equally well on both sides, and since, on the circle, the horse is set to lead on the inside leg we have an opportunity to insure the gallop lead on either foot. 
Increasing the gait from a trot on a circle furnishes therefore the means of fulfilling the two essential conditions just cited.

The aids to be used are both legs and the outside rein. The two legs, by steadily forcing an increased gait, push the horse into the gallop. A slight tension on the outside rein prevents the horse from swinging the haunches out, and consequently precludes a false lead or a disunited gallop.

The circle is the best means to give the gallop lesson when the squad to be drilled is rather large in numbers.

Besides the advantages already enumerated, troopers are enabled to work without interfering with each other, in spite of the difference in speed which manifests itself in the gallop of young horses. But if the number of troopers working in the hall is limited it is possible to secure the lead on the desired foot by increasing the gait from the trot at the corner, or on the completion of a flank movement, or at the end of a movement to change hands.

The gallop must be attained at the moment the horse begins the change of direction; for if he does not relinquish the trot until the change of direction is completed his haunches can easily swing out and the favorable opportunity is lost. 


\section{XIV.}

Backing-Method of execution.-The first lesson in backing may be given dismounted and in the following manner:

Being on the left side, with the reins in the left hand and the whip in the right, stimulate the hind quarters by a touch with the whip and take advantage of this mobility to exact one or two steps backward.

The horse should be made to move to the front again immediately by leading him forward with the left hand, and, if necessary, by touching him lightly with the whip.

To give this same lesson mounted, begin by closing the legs as in moving to the front and then move the horse backward by leaning back slightly and by pulling on the reins with gradually increasing force.

Here we see a striking example of the principle of starting everything with the movement to the front. The action of the legs before the action of the hands is a fundamental idea to be inculcated in the mind of every trooper. In backing, the legs are used first to produce the movement to the front and the hand is used next to transform the forward impulse into a backward movement.

After a few steps backward, start the horse forward again, halt him and caress him.

If a horse refuses to obey, the instructor takes him by the reins and causes him to execute the movement as in dismounted work.

If the horse braces himself on his hind legs at the moment that the hand acts to make him move backward, the instructor moves him forward a step or two or makes him swing his haunches slightly and takes advantage of this mobility to force him backward. 
This movement is well executed when the horse moves backward step by step and voluntarily moves to the front again as soon as the trooper releases the hand.

If, instead of backing slowly and step by step, the horse hurries the movement and is about to come down upon the haunches, the trooper promptly stops all action of the hand ${ }^{a}$ and corrects the horse by attacking him vigorously with the legs or with the spurs to push him forward again.

This exercise to be insisted upon in what cases?Backing is a suppling exercise for the back as well as the haunches, and it is an indispensable movement for the saddle horse. Yet it should not be abused, particularly in the early stages of training, as resistance will eventually be developed. Moreover, it is not suitable for all horses indiscriminately but should be used especially for those that have difficulty in bringing the hind legs under or that have too much weight on the forehand.

Individual work (at will).-Nearly all instructors have the bad habit of grouping young horses too much. The greater part of a drill is devoted to work with fixed distances, which gives the horses the idea of sticking in ranks. We have already said that it is better to work without regard to distances. And from the very beginning it is also essential to execute all movements in both directions and at will. If, in addition, we give a few outdoor rides in pairs, the young horses will become quiet, free movers and the remainder of the training exercises will be that much easier.

Condition of the horse at the end of the work in the snaffle bridle.-At the end of instruction in the snaffle bridle, the horse should be willing on the road and tranquil in the riding hall. He executes correctly the movement

$a$ As a matter of fact the trooper has probably lost all action of the hand because in this faulty movement the horse is invariably behind the bit. 
of haunches in, shoulder in, and two track work at a walk and at a slow trot. He takes up the gallop easily on either foot by increasing the gait from the trot. He has found his balance while moving freely to the front, a double condition which is satisfactorily fulfilled if he keeps the reins taut without ever bearing on the hand. His gaits are clean; he can lengthen the walk without jigging and the trot without becoming disunited; his wind has been developed and he can keep up a lengthened gallop for several minutes.

When this entire programme has been carried out and especially when the horse begins to pull on the hand, it is time to take up the double bridle. 


\section{$\mathrm{XV}$.}

Instruction in the double bridle.-The instructor's first care must be as to the manner in which the horses are bitted. A mild curb bit should be selected; that is to say, a bit with large cannons, a low port (only slightly restricting the freedom of the tongue) and short branches. The bit should be placed in the mouth high rather than low and the curb chain should be left long so as to facilitate at first a swinging motion of the bit. When the horses bear freely on the curb bit and when they submit to this new mouthpiece just as they formerly received the effects of the snaffle, the curb bit may be lowered to its proper place and the chain tightened to customary tension.

If the horse has a sensitive mouth, it is well to replace, for a time, the ordinary curb by a broken curb. ${ }^{a}$ The latter gives a mouthpiece more severe than the snaffle, but milder than the curb and the horse also becomes accustomed to the chain. The broken curb should be kept on for a certain length of time and may be resumed later if, during the course of training, it is noticed that the horse has a tendency to get behind the bit.

Successive steps to accustom the young horse to the curb bit.- In the first lessons in the double bridle, work should be begun on the snaffle bit. When the horse has settled down and is well in hand he can be ridden on the curb. It is to be remarked, and the remark is important, that bending lessons are never to be given in the early stages of work on the curb. For these lessons you must wait until the horse fearlessly accepts contact with the bit and tightens the curb reins as he formerly did the snaffle reins. If this method of procedure sometimes

$a$ A curb bit with snaffle mouthpiece. 
has the drawback of producing mouths with little feeling, we guarantee that it is less difficult to supple a part that presents stiffness than to make a part firm where all resistance is lacking.

To attain this bearing on the bit the following schedule should be followed:

(1) Ride the horse with the reins in both hands, placing the snaffle rein outside, under the little finger. (See Question XXV.)

(2) At first, during work at a walk and later during work at a trot, ride the horse with the curb rein alone; the reins may be held in one hand or in both hands.

(3) Finally adopt the ordinary method of holding the reins.

With each of these different methods of holding the reins the horse must be made to repeat simple movements with which he is already familiar.

Moreover, the horse should be frequently put back on the snaffle alone and be ridden at extended gaits in order to restore the confidence that he may have lost in beginning lessons on the curb.

During this preparatory period the legs play an important rôle. It is essential that the curb bit should produce upon the horse no slowing or backing effect and that the forward movement produced by the legs should overcome any tendency in the other direction which might be the result of the first use of this bit.

Bending lessons.-As previously stated, bending lessons should not be begun until the horse has become thoroughly accustomed to his new mouthpiece and fearlessly accepts contact of both bit and chain.

Before setting forth a schedule of bendings, it will be advisable to cite the following principles relating thereto:

(1) Never slacken the gait during bending lessons. The hand does not pull the horse back; the legs push him forward until he encounters the bit when a bending results. 
(2) Bendings with the snaffle bit should not be made except with one rein alone. Both snaffle reins are used in order to raise the head and to support the horse and therefore they should never be combined to exact bending.

(3) It is just the reverse with the curb bit, the reins of which are rarely separate in their action. The main object in view is a light feel on both reins.

(4) Do not bend the neck (laterally). In setting the head the upper part of the neck is involved and that is generally enough.

(5) Frequently follow up the bendings by easing the hand and as soon as the horse has extended his neck to the full extent, exact another bending with the head down.

Bending lessons with the double bridle should be taken up according to the following schedule:

(1) With the snaffle bit.-Flexing the jaw by the use of one rein; setting the head to the right and to the left (as in a change of direction).

(2) With both snaffle and curb bits. - Lateral flexion by the use of both right reins (XII); lateral flexion by the use of both left reins; setting the head by the use of both right reins; setting the head by the use of both left reins.

* * * * * * * *

(3) With the curb bit.-Flexing the jaw by use of one curb rein; flexing the jaw by the use of both curb reins (direct flexion).

The most important bendings are: (1) Setting the head by use of one snaffle rein; (2) direct flexion (of the jaw) by use of both curb reins.

Dismounted bending lessons.-Dismounted bending lessons should be the exception. If obliged to resort to them, they should be curtailed to the two following:

(1) Flexing the jaw.-Executed by taking one or both snaffle reins in the hand in front and one or both curb reins in the hand in rear. 
(2) Raising the head by the use of the snaffle. The trooper stands in front of the horse, facing him, and takes in each hand one of the snaffle reins, grasping it near the ring; the wrists are gradually raised until the horse's head and neck reach the desired elevation. The horse must stand still and must not back; if he starts to move to the rear, the whip is used to move him to the front again.

\section{DEFINITIONS.}

In hand.-The horse is in hand after he has completed and fully understands the bending lessons and when he yields willingly to the effects of the bit.

Lightness.-Lightness has been defined in answer to Question VI. It is the correct balance of the horse that obeys promptly and easily all impulses given him by his rider.

The set (Le placer) is the operation that places the center of gravity in the position required for the execution of any desired movement.-St. Phalle.

The gather (Le ramener).-To gather is nothing more or less than to set the forehand. When the horse carries his head and neck well up, the face approaching the vertical and the jaw flexible he is said to be in the position of the gather (or is gathered).

The assemble (Le rassembler).- The assemble consists of the gather perfected by bringing the hind legs under. The set of the forehand is combined with the set of the hind quarters. ${ }^{a}$

$a$ The horse can be gathered at a halt although he should be taught the correct carriage of the head and neck at a walk, in which case there will be no chance of backing. On the other hand, the assemble, the highest form of collection, can be obtained only when the horse is in motion; the horse is assembled in the half halt to be sure, but this position can be held only for a moment before the horse moves again. St. Phalle says: "The set, as will be seen, is inseparable from the in hand and the assemble." For instance, in the half halt the horse is assembled; he is also in hand, ready for any indication of the bit and he is set for movement in any direction.-The Board. 


\section{XVI.}

Easing the hand on the curb bit.-We have previously discussed the easing of the hand on the snaffle bit. The suppling exercise is the same when made on the curb bit, but in this case it should be followed by raising the head again.

The horse having yielded the jaw, loosen the fingers and continue the action of the legs in order to push the horse gently in pursuit of his bit. From the very beginning of training he has grown accustomed to lean lightly on the bit, and he therefore extends his neck and lowers his head to recover this customary support.

The extension of the neck will be sufficient and will be well executed whenever the horse, without increasing or decreasing the gait, extends his nose downward and forward to the level of the knees and keeps his jaw flexible.

The raising of the head is effected by carrying the hands forward and pulling upward on the reins, the legs still preventing any slowing up.

These suppling exercises should be repeated at a walk, trot, and gallop, and on the three lines.

Easing the hand is an exercise suitable for horses too high in front, with a high neck - that is, either upside down or ewe-necked-and for those with weak hind quarters, predisposed to injuries. It should be used very sparingly with horses that are high behind, especially if the withers are low and sunken, the shoulders straight, the neck thin, and the head large.

What should be understood by give and take-Action of the fingers on the reins.-As the horse should always be in close touch with the hand of the rider, the expression 
give and take has a certain significance which should be clearly stated.

Take does not consist in drawing the hand back and give does not mean carrying the hand forward and releasing the reins.

Assuming the permanent contact which should exist between the horse's mouth and the rider's hand, take means to fix the wrist and tighten the fingers at the moment of halting or of half halting; give means to relax the wrist and loosen the fingers without losing touch with the horse's mouth; if the horse has been well trained, touch will not be lost, because the horse will himself feel for his rider's hand.

Any slowing of gait should therefore be the result of the action of the fingers on the reins. If this action is insufficient, it must be reinforced by carrying the upper part of the body backward; but any movement of the elbows should be avoided, as this is the unfailing symptom of the unskilled horseman.

Necessity of frequently returning to the lesson of going straight ahead.-All these bending lessons made on the curb bit, these halts and half halts, only too often result in slowing the horse and in diminishing any desire to go ahead that he may have acquired.

(This is commonly called "steam," and is manifested by a proper voluntary tightening of the reins. The horse with "no steam" is voluntarily behind the bit.-The Board.)

It is therefore necessary to resume frequently the first lesson of the legs - the lesson of moving straight ahead. The horse should be attacked vigorously with the calves, being careful to fully loosen the fingers, so that he shall have complete liberty to escape to the front.

Lesson with the spurs. - With horses that hold back, that are too cold (phlegmatic), or that do not respond to the legs the spurs should be used. The lesson with the 
spurs does not occur at any fixed period, but is given when the occasion presents itself. If the horse is behind the legs (see Question XXVIII), put him at a trot in order to have him securely in motion (not liable to stop), and then let him feel the spurs by vigorous and repeated action until he leaps to the front.

Here it is particularly important to pay attention to the hand; you must not contradict with the hand what you demand with the legs, but must let the reins slip as much as is necessary to enable the horse to extend himself freely.

With certain horses it is sometimes prudent to grasp the pommel of the saddle when giving the spur lesson. The rider is then more certain of not contradicting himself and the lesson thus administered is sure to be profitable in the training of the animal. 


\section{XVII.}

Work at the trot-Rising to the trot.-The rider should always rise to the trot unless the slowness of the gait renders it impossible or, at any rate, difficult.

To rise to the trot, the rider inclines the upper part of the body forward and takes a firm grip with the knees in order to avoid throwing his whole weight into the stirrups and in order to have the lower legs perfectly free. He then allows himself to be raised by the thrust of one diagonal pair of legs, the right for example (i. e., right fore and left hind); he avoids the thrust produced by the planting of the left diagonal pair and drops back into the saddle just as the right pair is replanted, which raises him again.

The rider thus avoids every other thrust, tires himself less, and tires his horse less.

Necessity of frequently alternating the diagonal pair from which the rise is made.-But unless he is careful, he gradually acquires the habit of always rising from the same pair, or, as it is commonly expressed, of trotting on the same shoulder, and this habit has serious drawbacks.

(1) The pair from which the rider rises becomes much more fatigued than the other because it raises and thrusts forward the weight of both horse and rider; whereas the other pair, which acts while the rider is in the air, has only the weight of the horse to thrust forward.

(2) Moreover, the diagonal pair which thrusts both horse and rider can not project the horse as far as the pair which acts while the rider is in the air. Thus, if the rider is trotting on the right shoulder (i. e., is raised by 
the right diagonal pair), the thrust of the left diagonal pair will be the greater, and, since the thrust acts in the direction of the other diagonal, the right shoulder will gain more ground than the left. From this there results, after a certain length of time, a disagreeable irregularity in the gait.

The results explained in the second remark above may be practically utilized. If the rider discovers that his horse trots unevenly and advances one shoulder more than the other, he should rise habitually on the shoulder that gains less ground until the fault is corrected.

These results may also be utilized to correct the fault of a horse always leading with the same foot at a gallop. Suppose, for instance, a horse that always gallops on the right foot: to lead with the right foot the horse sets the right shoulder in advance of the left. If, therefore, the rider persists, for a certain length of time, in rising from the left diagonal pair, the left shoulder, as has been explained above, will be pushed further forward than the right and the horse will be in a position at a trot that will induce him to lead with the left foot at a gallop.

From the preceding explanations it is evident that the rider should know how to trot his horse on either shoulder and to change shoulders without changing gait if he wishes to develop the animal's efficiency equally and have him always perfectly straight.

The only exception is when the legs of one diagonal pair have been injured and they can be saved by rising from the other.

Lengthening and shortening the gait at a walk and trot.-Lengthening and shortening of gaits must be executed gradually and by the steady use of the aids. The lowering of the head and the extending of the neck assist in producing a lengthened gait. The raising of the head and curving of the crest favor a shortening of the gait. 
In all changes of gait the rider must accommodate his seat to the movements of the horse. The lengthening of the trot should be moderate and of short duration. By demanding more than the horse is equal to, an irregular gait will soon be developed and this will be difficult to correct later. 


\section{XVIII.}

Work at the slow trot.-In one of the first answers we mentioned the utility of the trot and explained the advantages in training resulting from the use of this gait. We can only repeat here what we have said before-the slow trot especially gives excellent results in the last stages of training. Suppling exercises for the haunches, shoulders, and jaw, when executed at this gait produce rapid progress in the horse; they increase his strength and suppleness by forcing him to acquire and preserve his balance.

Small circles.-Small circles lower the horse's croup; the inside hock is necessarily brought under and the outside shoulder is developed because it has a greater distance to travel. Moreover, this work on a restricted circle enables the rider to set a horse that experiences difficulty in bending the body and it aids in breaking up the contraction of the horse that pulls too hard on the hand.

Small circles should be rarely used with horses that hang back, for it is to be noted that on the circle they are especially prone to get behind the bit. Nor should turns be used too much with young horses with blemished or worn-out hocks. As for the aids to be used, it depends upon whether the horse has a tendency to let the haunches swing out or the reverse-to let them drag inside. In the first case the inside rein and the outside leg should predominate; in the second case the important aids will be the inside rein and leg.

Serpentines.-Serpentines produce about the same results as small circles, but in addition they accustom the 
horse to pass from one set (position) to the other easily and while advancing.

Two-track work.-Two-track work at a slow trot on the diagonal of the hall is another method of suppling the hind quarters and bringing them under; it is an excellent preliminary to the gallop lead.

Halts, half-halts, and backing.-When the horse moves freely and begins to be balanced and regular in both gaits, the walk and trot, we must take up the elements of the assemble, which is the gather perfected by bringing the hind legs under.

We begin by numerous halts, the action of the legs always preceding the action of the hand, and by this means alone the hind legs are gradually brought toward the center. If at the moment of halting the horse is contracted and endeavors to bore on the hand, the rider must keep up his action and exact a step or two backward in order to overcome all resistance. He must then promptly move the horse to the front again to avoid his sitting down on the haunches.

Half-halts are made according to the same principles, but the opposition of the hand is less marked than in halts. If the horse proves to be obedient, loosen the fingers and extend him; if, on the contrary, he resists the half-halt, keep up the action of the aids to the halt or even to backing.

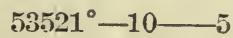




\section{XIX.}

\section{WORK AT THE GALLOP.}

Progressive method of perfecting the gallop lead on either foot.-(1) Taking up the gallop by increasing the gait from the trot.-In .Question XIII we explained how, in the early stages of training, the gallop should be exacted by increasing the gait from the trot. This early lesson repeated every day will have accustomed the horse to some extent to the gallop, and he will take up the gait readily to the right and to the left, on the circle or at the corner, without the necessity of prolonged pushing from the trot.

(2) Taking the gallop from the slow trot by lateral effect.-We now reach the second step. This new lesson should still be assisted by a somewhat restricted circular movement and the rider will exact a gallop only at the end of a circle or at the corner.

The difficulty of execution will then be slightly increased by requiring the same leads on a circle of greater radius or at the end of a diagonal of a half turn or of the diagonal of the change of hands.

(3) Taking the gallop from the slow trot by diagonal effect.-The series of leads made by lateral effect on small circles, circles and at the end of oblique lines will again be exacted by diagonal effect, and we thus gradually reach the gallop lead on a straight line, being careful to always divide the movement into two parts; first the set and then the impulse that produces the gallop. Thus, for the gallop lead with the right foot.

(a) Collect the horse to the right and pull diagonally on the right rein in order to restrain the left shoulder and 
to free the right shoulder; carry the body to the rear, throwing more weight on the left buttock; close the left leg to make the haunches yield to the right and to bring the right hind leg in advance.

(b) The horse having been set in this manner, close the right leg in order to add its effect to that of the left leg and to thus obtain, by the action of both legs, the forward impulse necessary to bring about the gallop.

(4) Taking the gallop from the walk.-A horse that takes the gallop readily from the slow trot will also take this gait without difficulty from the walk. The method of procedure is the same; that is, first set the horse and then push him into the gallop.

With horses that hesitate or fret, this last lesson should be subdivided by passing through the trot; that is to say, the horse will be set for the gallop while at a walk, from this set he will be urged into the trot, and from the trot into the gallop. Little by little this intermediate trot will diminish in duration until the horse takes the gallop immediately from the walk.

In this progressive method of obtaining the gallop lead on either foot, we began by increasing the gait from the trot and finished by taking the gallop from the walk because we are convinced that taking the gallop is easier in proportion to the speed of advancing. In our opinion, taking the gallop from the walk is the most difficult exercise and if insisted upon too early will result in horses that back or stand and resist. Our method appears, perhaps, rather long, but it has the advantage of producing horses that act smoothly, that take the gallop without fretting and without losing touch with the rider's hand. 


\section{XX.}

Where should the training of the troop horse stop?The training of the troop horse should stop after the gallop lead has been included. It is useless, or rather impossible to proceed further with the material available. A horse for the ranks, that goes straight and free at all gaits, that is easily handled in any direction and that takes the gallop lead readily on either foot, is in condition to satisfy all demands imposed in the service. But this elementary education is not sufficient to meet the requirements of an officer, who should always have a perfectly trained horse. It is therefore important to point out what movements will perfect and complete the animal's schooling.

The false gallop.-Galloping false is used as a means of lowering the croup, of balancing the horse and holding him in his gallop. There are no special instructions about leading with the outside foot; the only difficulty is to pass the corners without the horse becoming disunited. To avoid this, the haunches must be strongly supported by the inside leg and the horse must be held set by the outside rein (supporting rein) in order to free the shoulder on that side and keep it in the lead. In making a change of direction when galloping false, the hands should be slightly lowered (eased), so that the movements of the hind quarters will not be hampered and checked.

(It is also most important to forcibly keep up the gait. If allowed to slow up, the horse is almost certain to escape from the aids and change the lead.-The Board.)

Alternating the gallop at short intervals.-The gallop leads comprise all the essential principles of training: Setting the head, the neck, the shoulders, and the 
haunches, bringing the hind legs under and moving to the front. This very complexity shows their importance. It will therefore be readily understood that gallop leads, alternated at short intervals, will rapidly perfect the young horse's training and, moreover, that this is the best method of paving the way for the lesson of change of lead.

Change of lead.-Change of lead is nothing more than exacting the gallop lead when the horse is at the gallop. It is the most difficult of leads and must not be attempted until the horse is thoroughly confirmed in the gallop lead from the trot and walk. If the lesson of change of lead is given too soon or if the rider is too exacting at first the horse will slow up and become uncertain in gait. $\mathrm{He}$ will learn the trick of holding back and especially of galloping disunited; hence, all the benefit of preceding lessons will be lost.

To bring the horse up to the change of lead, gradually decrease the intervals between the alternate leads exacted from the slow trot. The set of the horse must be changed before he returns to the trot. Thus, for instance, if the horse is galloping right, set him with the left diagonal effect (right leg and left supporting rein). The change of set causes the horse to balance himself and brings him down to the trot (where he feels steadier), but if the lower aids continue to force the gait the horse will take the gallop with the left lead.

This is the analysis of the change of lead. Little by little the length of time of the intermediate trot is diminished until the change of lead in the air is obtained.

The lesson of change of lead can be given on the track of the riding hall or on a circle. At first it is advantageous to lead off with the outside foot and then attempt the change of lead to the inside foot. This plan is especially applicable to work on a circle.

In all this work, the thing to be avoided is a desire to progress too rapidly. If the horse resists, you must not 
be bullheaded; you must begin again and take up the analytical parts of the movement, going back to the simple gallop leads. By insisting too strongly you teach the horse to resist the reins and legs and destroy what lightness he may have acquired. Moreover, the horse's resistance proves that you are attempting the change of lead too soon and that he is not yet up to it.

Continuation of training-Work at the slow trotGallop exercises.-Review the instructions given under Question XVIII on what concerns the trot and what has just been said about work at a gallop. Work at the slow trot on the three lines will develop the strength and suppleness of the horse; alternating gallop leads with short intervals, exacted from the trot, the walk, the halt, and when backing, will finally perfect his balance and obedience; he will then be well trained.

But this work must not be abused. Riding-hall work should be of short duration. The horse should be often taken out, galloped over good ground and jumped over obstacles. It must not be forgotten that the desirable qualities in an officer's mount are that he shall he perfectly willing, go perfectly straight, and remain perfectly calm, all of which qualities would disappear if he were kept constantly shut up in a riding hall, working at slow and shortened gaits. 


\section{XXI.}

\section{HOW YOUNG HORSES ARE TAUGHT TO JUMP.}

Jumping when at liberty.-Young horses may be taught to jump when at liberty or on the longe.

Jumping at liberty is ordinarily practiced in a straight chute, in which are placed several obstacles-at least one ditch and one bar. The horse is led quietly to one end of the chute and caught at the other end by men who stop him without frightening him and then offer him oats as a reward. Near each obstacle is stationed a man with a longeing whip ready to urge horses that hold back and hesitate; but the use of the whip should not be abused as it bewilders the animals and after a few lessons is ordinarily no longer required.

Jumping at liberty produces horses keen and straight on their jumps. The drawback is that the animals jump too quickly and acquire only a certain amount of skill; for, instead of observing the obstacles that they are taking, they have only one idea and that is to get out of the chute. The system is especially suitable to train horses for steeplechasing.

If the jumps in the chute are high, it will be better not to send young horses through until after they have had several preliminary lessons on the longe.

Jumping on the longe.-Jumping on the longe is a perfect lesson to train a horse for obstacles. Drilled by this method, the horse is cool and clever and forms the habit of observing the obstacle. It is the best system for service mounts and hunters.

This lesson may be given in the hall or in the open and in the following manner: 
High jumps.-Place a bar on the ground. Holding the longe in one hand and the snaffle reins in the other, lead the horse and step over the bar with him several times in succession in both directions. When the horse no longer shows hesitation, move away from him a little, put him on a circle and make him cross the bar on the longe. Later the bar is gradually raised.

To give the lesson properly, it is necessary:

(1) To let the horse assume, at a short distance from the bar, whatever gait suits him, and immediately after he jumps to make him resume the original gait of the circle.

(2) To advance a step or two toward the obstacle and to open the fingers, so that the longe may slip through the hand while the horse is approaching his jump and will not be too taut when he leaps; he must never be hampered, but must have complete liberty.

(3) To take up the horse on the longe again gently, return him to the circle and to the original gait.

It is a good plan to practice the horse in jumping on the longe at a walk before trying him at the trot and gallop. At the walk the horse can best estimate the jump and the amount of effort necessary to clear it; at the walk he also learns how best to assist himself with his head and neck. Jumping at the other gaits then becomes less difficult.

Broad jumps.-The method of procedure and the precautions to be taken are the same as for high jumps. Begin with very easy ditches and progress to broader and more difficult ones. The first time do not prevent the horse from stopping to examine the ditch. He will feel the ground, bring up his hind legs little by little, and after much hesitation will finally clear the ditch. This feeling for firm ground is allowed on the first trials only, and as soon as the first apprehension has disappeared, any halting in front of the obstacle must be energetically corrected. Young horses are much more disposed to hesitate at breadth than height. 
Jumping mounted.-After horses have been trained in jumping at liberty and on the longe, they are made to jump mounted.

At first they must be in the snaffle bridle. Always begin with insignificant obstacles. In the riding hall, place the bar on the ground and afterwards raise it gradually according to the confidence shown by men and horses. Out of doors, start with very easy jumps and work up gradually to the class of obstacles that every service mount should clear. 


\section{XXII.}

To accustom young horses to the saber.-For the first few days the saber should be worn on the belt and not slung to the saddle. In this manner the saber may more easily be held away from the horse, in case he becomes too excited, and any dangerous struggles resulting from prolonged contact may be avoided. With very nervous horses, the saber, instead of being attached to the belt, may be held in the hand and the lesson can then be easily continued or stopped at will.

The first lesson should be given in the middle of the period of work when the horse's nervousness has already been worn off.

The saber is next slung to the saddle; as soon as the horse has become accustomed to it, the different movements of the saber exercise should be executed until absolute indifference is obtained.

To accustom horses to firearms and noises.-Several methods are used. One of the best is to place the mounted troopers on a large circle; dismounted men are placed in the center, some with revolvers, flags, and trumpets, others with boxes or sieves of oats. At a given signal the noises cease and the horses are turned to the center of the circle where the oats are offered to them.

This same exercise is repeated on circles of smaller radius and when the horses show no further anxiety, they are turned into the center and fed oats while the noises continue.

Another plan is to place in line the dismounted men with the revolvers, flags, and trumpets and have them march around the drill ground. The young horses, also 
in line, follow them about, at first at a distance, gradually approaching and finally eating their oats in the ranks.

However, it is not necessary to enter into minute descriptions of details. It will suffice if the following caution is observed:

Avoid a struggle by starting at a distance from the dismounted men and do not insist brutally on the occasion of a horse's first fright.

Swimming exercises.-Swimming exercises are difficult to carry out, and the results obtained are not always commensurate with the danger to which the men are exposed.

If, however, the horses must be made to swim, the following schedule should be followed:

(1) Make the horse swim, holding him at the end of a longe attached to the halter. In this way you will be more certain to avoid any jerks that would cause him to make false movements. This remark is very important, for if a horse in the water is brought up short he will splash in his struggles and may easily lose his head completely.

(2) After the horses exhibit a certain amount of confidence, they should be mounted, bareback and in snaffle bridle, by men who are excellent swimmers, and then taken across a rather narrow stream. In order to have this exercise carried out under favorable conditions, the banks of the stream should have a gentle slope so that the horse can enter the water gradually, get out without difficulty and not be forced to swim more than a few yards.

(3) The same exercise is repeated once or twice only, with the horses saddled and bridled. 


\section{XXIII.}

\section{VARIOUS FAULTS OF SADDLE HORSES.}

The hot-headed horse.-Ride him alone, calm him by the voice and by patting and pull as little as possible on the reins. Bring down the head and neck by protracted periods of trotting. Then execute in the hall serpentines and figures to accustom the horse to submit to the pressure of the legs and to obey the aids readily.

The jigging horse.-Begin by giving the leg lesson until the horse moves freely to the front. When he is well up on the bit, make him half lower the head, keeping the reins taut but following the balancing of the head and neck. Whenever the horse resumes the trot, push him sharply with the legs and then, carrying the body back, exact a half halt to bring him down to the walk.

The horse that gallops when he should trot.-It is almost always because he holds back or because the hind quarters are overloaded that a horse, even a hot-headed one, makes trouble at the trot. In either case, make him extend his neck and every time he rises to the gallop push him with the legs but do not pull on the reins. Then carry the body back, pulling gently on the reins and, by means of the legs, holding the horse's haunches perfectly straight. Loosen the fingers at the first strides of the trot and keep the body erect with the legs firmly set.

The puller.-Being at a walk, execute half halts with lateral effects; when the horse has yielded, let him straighten himself again and resume the original gait. Repeat this same lesson, first at a slow trot and then at the regulation trot. In this way the puller's rigidity is broken up, he is forced to bend, and to bring his hind legs under. 
Work at a slow trot on small circles, serpentines, and diagonals, halts, and half halts, make up an excellent schedule of exercises for the horse with ioo much weight on his shoulders and that pulls too much on the hand.

The star gazer (the horse that pokes his nose out).A horse with this fault has a rigid jaw and holds his head high, approaching the horizontal. A bad neck conformation induces this fault, but it generally results from bad riding, the horse being afraid of the hands.

To correct this fault set the hand, that is to say, hold it stationary above the pommel of the saddle, the reins remaining taut; close the legs to push the horse up to the bit and tighten the fingers on the reins until the horse lowers his head slightly; loosen the fingers immediately and slacken the reins. Begin again and continue the lesson until the horse yields at the slightest pressure of the fingers and understands thoroughly that the hand is severe when he pokes out his nose, but relaxes completely as soon as he sets his head properly.

The horse that fights the bit (throws his head).-This fault is found only in the horse that holds back because, in order to make the movement of the head, he must diminish the gait slightly.

To correct the fault, it is not wise to use the hand only, as is frequently done, because any effect of the hands tends to a further decrease of gait. The most rational and at the same time the most certain method is as follows:

Make the horse move freely and push him energetically with the legs at the very moment that you feel that he is about to throw his head; at the same time loosen the fingers to allow the neck to be extended and the head lowered. If this plan is not sufficient, hold one rein taut and set the hand that holds it. This method is effective because the head movements can be made only sidewise and become very painful. 
The horse that lowers his head against his chest.-It is hard work to correct this fault and much more difficult to raise the head than to lower it. To raise the head, begin by extending the neck in order to open the angle it makes with the head. When the neck is well extended use the snaffle reins to gradually raise the head, watching carefully that the horse keeps his muzzle to the front. The upward pull of the snaffle reins must be felt at the corners of the lips; the legs must act vigorously to prevent any slowing of the gait. Exact little at first and ease the hand as soon as the horse raises his head slightly and yields his jaw. Give this lesson several times each ride and at all gaits until the horse holds his head at a proper height whenever the snaffle reins are tightened and the legs closed.

Dismounted bending lessons also give good results. The trooper stands facing the horse, and taking one snaffle rein in each hand steadily raises his hands until the horse lifts the head without backing.

The horse that rears. - This fault begins with halting and squatting. Hence the first thing to do is to prevent this backward movement by a counter attack-that is, by an attack that will produce a movement to the front and that will throw weight on the forehand.

If the horse resists the forward movement, turn him on the spot so as to disorganize the forces necessary in rearing. When the haunches move laterally no part of the horse can be contracted and he is therefore prevented from throwing the weight on his hind quarters.

The kicker.-If a horse has the bad habit of kicking, use the snaffle bit to prevent his lowering the head and at the same time push him vigorously with the legs.

It is a mistake to always hold up a kicker's head; it frequently happens that kicking is caused by some pain in the back or hocks, and, if so, raising the animal's head will merely increase his irritability and incite resistance. 


\section{XXIV.}

* $\quad * \quad * \quad * \quad * \quad *$

Requirements of a good saddle.-A good saddle should satisfactorily meet the following requirements:

(1) The padding should be done in a way to secure perfect balance of the saddle. Too high behind, the saddle will throw the whole weight of the rider into the stirrups. Too high in front, it will throw him back and diminish the grip of the thighs and prevent proper set of the knees.

(2) The pommel arch should be wide enough to allow the saddle to be used on nearly all horses and to be set far enough back.

(3) The seat should not be too flat and the rider should not feel the outer edges of the bars of the tree under his thighs.

(4) The straps for the girth should be set well forward. If the line of traction of the girth were too far to the rear the saddle would rock and, rising in front, would work up toward the withers.

How a horse should be saddled. - The saddle should be placed far enough back, but it is impossible to give any fixed rule. Its proper place depends upon the conformation of the horse. A horse with a good back and a well-marked girth place is easy to saddle; it is the reverse in the case of one with short ribs or big belly or hollow shoulders.

The matter of saddling, although often neglected, is of great importance. Everything in riding hinges on balance, and balance will be handicapped from the start if the rider is seated too close to the withers and is unduly overloading the forehand. 


\section{XXV.}

Holding the snaffle reins.-When the horse is ridden in the snaffle bridle, the rider takes one rein in each hand-

the reins coming in on the underside of the little finger, and coming out over the second joint of the forefinger, on which the thumb firmly holds the rein; the other fingers closed on the reins, nails toward the body. *** Hands about 6 inches apart, on a level with the elbows, backs straight up and down and outward.-United States Cavalry Drill Regulations, paragraph 195.

With the double snaffle, the rider takes two reins in each hand. The reins of the lower snaffle bit (corresponding to the curb bit) pass between the third and little finger; the reins of the upper snaffle bit pass under the little finger, and both reins are held upon the forefinger by the thumb as explained above.

* * * * * * * *

Holding the double bridle reins.-With horses that pull hard, and more especially with horses that struggle or fight, it is a distinct advantage to hold the reins in English fashion, that is, with two reins in each hand as described above for the double snaffle. ${ }^{a}$

$a$ To take the double bridle reins in one hand (the left) turn the right wrist to the left until the back of the right hand is up; move the right hand to the left and insert the second finger of the left hand between the two reins (right snaffle rein uppermost). All four reins are held upon the second joint of the forefinger by the thumb. To pass the reins from the left hand to the right hand, turn over the back of the left hand to the right and insert the extended fingers of the right hand between the reins in such a manner that there will be a rein above each finger (left snaffle rein uppermost), the four reins coming out under the little finger instead of above the forefinger. If the hands are habitually held back up, as is frequently done, the passing of the four reins from one hand to the other is much simplified.-The Board. 
Handling the reins.-It is absolutely necessary to accustom riders to handle the reins skillfully.

All work on the reins must be varied, smooth, and progressive. These results can not be obtained unless the rider is thoroughly supple in the shoulders, arms, and wrists and has clever fingers. The reins must be changed from hand to hand, must be separated and reunited not only without jerks, but also without failing to maintain the proper tension.

It should also be added that handling the reins understandingly and skillfully is an indirect method of making a horse's mouth perfectly straight. Changing hands frequently will prevent the prolonged action that worries the horse and causes faulty bends of the neck. Riders who hold the reins constantly in the same hand and in the same manner always have horses with stiff necks set to one side.

$53521^{\circ}-10-6$ 


\section{XXVI.}

What is meant by the aids?-The aids are the different means employed by the rider to convey his desires or intentions to the horse.

Into what classes are they divided?-The aids may be divided into natural and artificial. The natural aids are the hands and legs; the artificial aids are: the spur, the whip, the voice, the pat, the longe, the longeing whip and the padded posts. ${ }^{a}$

The hands are called the upper aids and the legs, the lower aids. Some horsemen make use of the terms principal and supplementary to designate the natural and artificial aids, respectively.

From the standpoint of the execution of a movement the aids are classed as decisive and controlling.

The former are indispensable to the execution of the movement and have a dominating action; the latter are merely useful, and participate only in setting the horse to advantage and in making the movement regular.

A final division into lateral and diagonal aids results from the manner in which the aids are combined. In the first case, the rider uses simultaneously the rein and the leg on the same side; in the second case, he uses the rein on one side and the leg on the opposite side.

Function of the hands. - It is the business of the hands, through the medium of the reins, to communicate to the horse his rider's will, to regulate the horse's gaits, to halt him and to back him.

Their principal function is the control of the forehand, the impulse having been given previously by the legs.

a Les piliers are two padded posts to which the horse is fastened by a harness for instruction in the high school "piaffer" and in the different plunges and kicks of the "sauteur." 
Considered separately, each rein can produce four important and distinct effects:

(1) Front to rear effect.- The rider pulls on the two reins alike, without pressing them on the neck and without opening the wrists. If the horse is moving, he will decrease the gait or halt; if the horse is halted, he will move backward.

(2) Opening effect.-The rider opens the right rein by carrying the wrist to the front and right. The horse's head will be drawn to the right and he will move in that direction. This is the direct rein.

(3) Bearing or pushing effect.-By pressing the left rein against the neck, the mass (forehand) is pushed to the right and the horse faces in that direction-this is the indirect rein, sometimes called the supporting rein. ${ }^{a}$

(4) Opposing effect.-The rider opens the right rein lightly and then pulls either in the direction of the right haunch or in the direction of the left haunch. He is then said to set the shoulders in opposition to the haunches. The rein of opposition comes to the aid of the leg on the same side when the latter's action is insufficient or incomplete.

$a$ In the United States Cavalry Drill Regulations a horse is described as "rein wise when he obeys the lightest pressure of the rein on either side of the neck, the bit not being disturbed from its normal position." It is to be noted that the horse has learned to obey this pressure (third effect) through its association with the opening of the leading rein, as prescribed in paragraph 216, Drill Regulations (second effect). When the rider uses the direct or leading rein, there must be sufficient tension on the other rein to prevent the bit from "being disturbed from its normal position," and the other rein (la rêne opposée) is also pressed against the neck to support the action of the direct rein. In general, there must be combined action of the reins just as there must be combined action of the legs (see "Unison of the legs, in the next question), and this fact should be kept in view in the discussion of the distinct effects produced by the reins. The text reads: "Considered separately, each rein, etc.," which might be erroneously construed as "Each rein, acting alone, etc."'-The Board. 


\section{XXVII.}

Function of the legs.-The legs act on the hind quarters. Their business is to communicate the rider's will to the horse in order to move him straight to the front, to make him extend or increase his gaits, and to start him in movements of all kinds. It is also their special business to control the haunches, to restrict them to the direction pursued by the shoulders or to swing them in reference to the shoulders. Finally, they are used to collect the horse by bringing his hind legs closer to the center of gravity.

To recapitulate, the legs have three effects:

(1) To produce a forward movement.

(2) To swing the haunches in reference to the shoulders.

(3) To bring the hind legs under.

The simultaneous action of both legs produces a double pressure to which the horse should respond by moving to the front.

The action of a single leg, while it incites motion, forces the weight of the hind quarters toward the opposite side. Thus, for instance, if the rider closes his left leg, he produces two effects: a general forward movement of the mass and a right lateral movement of the haunches.

Unison of the legs. - Whenever one leg acts to swing the haunches, the opposite leg must receive the mass in order to limit and rectify the movement. The legs, therefore, should always be close enough to the horse to act without sudden jolts and to lend mutual assistance. 
A horse is in the legs when he obeys at the slightest indication and when the gentle closing of the calves is sufficient to make him move out boldly to the front. ${ }^{a}$

Perfect obedience to the legs is to be considered as the characteristic sign of successful training.

In the use of the horse everything is based upon the movement to the front; the upper aids merely utilize and direct the impulse produced by the lower aids; and if this impulse is wanting or is incomplete, the horse escapes more or less from the rider's control. We have said several times that the lesson of the legs must take precedence over all others and that it is necessary to return to this lesson every few minutes during the whole period of the instruction of the young horse.

A horse is behind the legs when he remains indifferent to their action either through sluggishness or unwillingness.

A horse behind the legs is, as a natural result, behind the bit. He is completely out of his rider's control; this is the beginning of obstinacy.

Length of stirrups.-Our regulations (French) say:

The stirrups are suitably adjusted if the tread of the stirrup is level with the top of the boot heel when the trooper is sitting properly on his horse, with the knees closed and the legs hanging naturally.

In his treatise on equitation, Count d'Aure admits the same principle but states it less precisely. According to him, "the tread of the stirrup, before the foot is inserted, should be at the height of the rider's heel."

In the Austrian cavalry the stirrups are worn somewhat shorter. Their regulations say:

The trooper adjusts the stirrups so that the tread shall be about 1 inch above the seam at the heels. If, from this adjustment, the trooper stands in his stirrups, there will be a space of four fingers between his crotch and the saddle.

$a$ In the United States Cavalry Drill Regulations a horse is described as "leg wise when he obeys the lightest correct combined action of the rider's legs." Although this definition is almost identical with the first clause of the definition of "in the legs" as given in this text, the second clause establishes the difference in meaning. To understand a signal is one thing, to be ready to move at the signal is another. 
The German regulations give the same instructions as the Austrian. (See also paragraph 247, U. S. Cavalry Drill Regulations.)

When the stirrups are too long, the rider is said to be on his crotch (fork seat); he loses all stability; his legs flap about the sides of the horse and act with neither strength nor accuracy.

When the stirrups are too short, they support more than the weight of the legs; they raise the knees and thighs and force the seat back. The trooper is then said to be hung up, and, although he has a stronger support in the stirrups, he is less secure, because he is not so far down in the saddle. Moreover, the legs necessarily become rigid; they lose all freedom of movement and in consequence all nicety (of action as aids).

The stirrups, then, should be neither too long nor too short. But of the two faults the latter is the more serious; a trooper can shorten his stirrups without anxiety, whereas he feels a certain reluctance about lengthening them. It is to be noticed that the man who loses his suppleness or his confidence always has a tendency to diminish the length of his stirrup straps.

Position of the foot in the stirrup.-At least one-third of the foot should be inserted into the stirrup; the heel should be slightly lower than the toe; the part of the sole of the foot included between the joint of the great toe and the little toe (ball of the foot) should rest upon the tread.

The support should be secured mainly on the inside portion of the foot; this method results in closing the knee and holding the lower leg in proper position. 


\section{XXVIII.}

Part played by the neck in equitation.-When a horse is left to himself and is free to apply his own natural methods, he makes uses of his head and neck as a balancer to keep his forces in equilibrium or to modify their action. If he wishes to go forward, he pushes out his head and extends his neck in order to shift the center of gravity in the direction of the desired movement. If, on the contrary, he wishes to go back, he pulls in his head and shortens his neck, thus starting the mass in the movement to the rear. In lateral movements, oblique or circular, it is the same; the shifting of the head or neck to the right or left prepares, favors, and controls the animal's action.

At a walk, the head and neck are in constant motion in order to take weight off the legs that are moving to the front and place weight on those that rest on the ground.

At a gallop, the balancer is alternately raised and lowered according as the horse is supported on the hind quarters or on the forehand and is extended or brought. in according as the gait is rapid or slow.

This shifting of the head and neck that we observe in the horse at liberty should be noted when the horse is ridden. The rider should be completely master of the neck, and when he gives his horse the signal for a movement should be able at the same time to set the neck in the position most favorable to the execution of the movement. The neck is thereiore a steering gear as well as a balancer, and suppling exercises that involve this region necessarily take up a large portion of the time devoted to training. But it is to be noted that these 
supplings must be confined to the upper part of the neck. The neck must always offer an elastic resistance, suitable to its functions. If it were too flexible and too easily moved it could neither react on the hind quarters nor control the movements of the forehand.

The kind of neck to select.-The importance of the part played by the neck shows the importance that should be attached to its good conformation. A rider should always select a long and powerful neck, with the head well set on. And it should be remembered that we said that in training it is more difficult to raise than to lower the head; a high neck branching firmly from a sloping shoulder will diminish the difficulties of training and will permit the rider to produce more easily a brilliant, well set up horse.

Different positions of the neck.-The neck should always preserve its muscled pose and even have a eertain amount of rigidity. Its position should be the same as that assumed naturally when the horse at liberty, is in high spirits, and standing still.

If, contrary to this principle, the experiment is made of raising the head and neck too high, the play of the shoulders may be freer, but, at the same time, the loins and all parts of the hind quarters will be weighted down and the haunches and hocks will be hampered in their action. As a result, movements of the hind quarters will be constrained, unequal, and jerky, and the gait will lose both speed and regularity.

If the neck is too low, the hind quarters will be more at liberty but will not (for that reason) fulfill their functions any better; for, since they can not be brought up toward the center of gravity except by a special, momentary, and forcible application of the lower aids, they will promptly go back again and will be relieved of the weight which is their proper share in an equal distribution of forces; weight, we repeat, that tends to set the hind quarters; weight that, when the neck is held at a suitable height, naturally and properly falls back from the shoulders upon the haunches. If the hind quarters are too free and do not carry their proper share of weight their action is not favorable to smooth gaits.

Therefore the position of the neck should be neither too high nor too low. The neck must be able to shorten or lengthen itself according as the face approaches or departs from the vertical. 
The head when drawn back should bend the neck without breaking $a$ it; 'when extended forward, it should stretch the neck without raising it. When the horse is posed in this manner, the reins will retain full power and both the front and hind legs will cooperate in any movements, either lengthened or shortened, that the rider may exact.-Count D'Aure.

Different positions of the head.-In order that he may feel with uniformity the touch of his rider's hand and in order not to impede his breathing, the horse's face should be set a little forward of the vertical. This position should be taken for ordinary gaits and for.simple and regular movements.

The more we wish to shorten the gait the more the face should approach the vertical plane; on the other hand, the more we wish to increase the speed the more the face should depart from this plane.

In these last two cases the position of the head may also be considered as normal since the gaits depend thereon.

The head may assume a faulty position; that is to say, one too near or too far from the vertical; this may be due to defective conformation of the forehand, faulty fitting of the bit, undue sensitiveness of the chin groove or bars, or finally, and this is most frequently the case when horses throw the nose into the air, to a defect in the conformation of some part of the hind quarters.

These faulty positions can be combatted by the rider not only by a judicious use of the aids, but by a careful selection of the bit, an attentive fitting in the mouth, and a studied adjustment of the curb chain.Count D'Aure.

Infiuence of conformation.-All horses can not be ridden in the same manner. General principles of conduct and training remain the same, but supplings vary according to the defects of conformation that must be overcome.

A horse of good conformation is easy to train; all that is necessary is to teach him the language of the aids, and when he understands everything becomes simple to him. When, on the contrary, proper balance is wanting, it is necessary not only to instruct him, but also, by means of protracted and well understood exercises, to establish an artificial equilibrium that will correct natural defects.

$a$ The bend should be near the poll; the rest of the neck remains practically the same in all positions, or, as it is called, "unbroken." 
A horse with croup too high and whose weight is on his shoulders will not be trained along the same lines as one with high forehand or weak hind quarters. In one case we must raise the head and force the weight back; in the other we must lower the head and load the forehand. A good horseman must therefore study his horse's conformation and adapt his methods of training to the kind of resistance he encounters. This, in order to develop in the animal, in action, a balance which is rarely to be found in young horses. 


\section{XXIX.}

Training for a military race.-It is impossible to lay down fixed rules for training a service mount to run a military steeple chase. The care of the animal as well as his work will vary with his breeding, but an officer or a noncommissioned officer training his horse must pay constant attention, in all cases, to-

(1) The amount of work.

(2) The condition of the legs.

(3) The appetite.

First. Amount of work.-Training a service mount for a military steeple chase does not involve such complete conditioning as is required in training a thoroughbred for a flat race. Moderate work should be sufficient to put him in condition, keeping in view the main object which is to bring him up to his maximum strength and energy on the day of the race. First, it must never be forgotten that the less the horse has of pure blood, the less he should be worked into condition for a speed test.

About two months are required to prepare a horse, following a well-chosen programme and working only rarely at full speed. It is better, if possible, to have the horse a little above condition to start with, that is, fat rather than poor, because it is easier to take off fat than to gain weight by building muscle.

Each day's work should be of about two hours' duration. Exercise should be given in the morning as far as possible, at any rate in summer, so as to avoid the heat and the flies. Give the horse one, or at most, two quarts of oats about one hour before work.

First and second week.-Exercise the horse at a walk; work him once or twice every day at a trot for a mile or 
two, and at a gallop for half a mile. Twice a week give him a mile at a very moderate gallop.

If the horse is too fat, give him a purge during the first days of training to decrease. the size of the intestines, and at the end of the first week give him a sweat to eliminate part of the fat from the tissues. (See Question VIII.)

Thin horses or small eaters do not need either purges or sweats.

Third and fourth weeks. - If the legs keep in good shape and the appetite continues good, increase the speed and duration of the gallops, diminishing proportionately the length of time at the trot. Twice a week give a good gallop, but not at full speed. A second sweat should be given at the end of this period if the horse is still too fat.

Fifth and sixth weeks. - Same work, increasing the speed and taking the horse once or twice over a distance nearly equal to that of the race.

Seventh and eighth weeks.-Give several gallops from one-half to three-quarters of a mile, increasing the gait during the eighth week at the end of the stretch. Give also two or three gallops about 2 miles long, but never force the pace.

Two days before the race, gallop from a half mile to a mile, increasing the pace as much as possible the last quarter of a mile, but of course without overtaxing the horse. The day before the race give him only a half-mile gallop at a moderate gait. The morning of the race exercise for an hour at a walk.

Training for obstacles is only secondary, provided the horse already knows how to jump. It is sufficient to take him over a few obstacles at an ordinary gait, from time to time, after the second or third week.

During training it is essential that the horse be calm and that he lower his head and stretch the reins without boring on the hand. 
It should also be clearly understood that the programme of work is subordinate to the horse's appetite and to the condition of his legs; the gallop must be replaced by the trot or walk, entirely or partly, every time the tendons become heated or the horse refuses his oats.

Second. Condition of the legs.-The horse's legs should be examined every day and handled with the greatest care. As soon as one tendon becomes more heated than the other decrease or stop the work and relieve the overworked part with douches, with bandages soaked in the "white lotion" $a$ or in water and arnica, until the heat has disappeared. Then change the work and replace the rapid gaits by the walk, increasing the duration of exercise. If the tendons heat again it is better to stop training entirely and thus avoid a strain that would lay the horse up for a long time.

Third. Feed during training.-As a general rule a horse never eats too much during training. But if he eats heartily and if his legs will stand it increasing the work is sufficient to prevent him from taking on too much flesh, and training in such a case will go on under the best possible condition. This, however, is rarely the case; increasing the work generally decreases the appetite, and it is difficult to make a horse eat more than 14 quarts of oats a day. As soon as a horse stops eating with relish, the gallop should be decreased or stopped, and resumed only when the horse cleans up his oats.

During training hay is an entirely secondary nourishment; 4 or 5 pounds a day are generally given. Bedding should always be abundant and extra good, so that, if his appetite suggests, the horse can eat some of it.

The ration should be gradually increased with the work, and given in three or four feeds. Oats that are not eaten at the end of an hour and a half or two hours should be taken away so as not to make the horse lose his appetite.

a Acetate of lead, I ounce; sulphate of zinc, 1 ounce; water, 1 quart. 
With light eaters mix carrots, bread, green forage, etc., with the oats, but in small quantities. A piece of salt in the feed box is often useful in creating an appetite.

When a horse, as is often the case, needs cooling (the counteracting of the heating caused by grain) he should be given two handfuls of sulphate of soda in a mash three or four days in succession. The mash is placed in the feed box after the evening feed and left there all night.

If a horse is a large eater and fills his belly with the bedding put on a muzzle after he has finished his feed.

A horse must be left absolutely quiet when eating; the evening feed should be the largest. 


\section{XXX.}

Conditioning a hunter.-I shall take the case of a horse that you have bought with the idea of using him for hunting. He is trained, has been worked, and comes from a dealer or any other similar source. His conformation appears good to you from the standpoint of service and his gaits are natural. $\mathrm{He}$ is in good condition, fat. It is spring or summer-June, let us suppose. You wish to condition your horse for the hunting season. What will you do?

First, run your hand all over your horse, but mainly over the body, and pay special attention to the croup and neck. If you find the flesh soft and yielding under the fingers, the legs rather round and pasty, have your horse saddled, mount him, and ride him into a ploughed field or upon a road deep with sand. Put your horse into a slow gallop, keeping him well in hand; make him work his hind quarters and bend his neck a little. The horse immediately begins to blow and in a moment is dripping wet. The sweat is white, and resembles soap suds. Do not go any further; your horse is not in condition, and you must require nothing further of him for the present. Take him quietly back to the stable and for two days put him on bran mash and diet, and on the third day give him a purge. Do not be afraid that I am going to overdo this last. Perhaps, if your horse is too fat, too heavy, I will allow you one more at the end of August, but that is all. For in sane hygiene you should avoid the pit into which many hunting horses in England fall, the destruction of the stomach and intestines by an excess of purges and of drugs intended to give an appetite. Moreover, in France our hunters must be in much finer condition than in England. They are not required to do the same kind of work. A hunter in England must withstand two hours of fast gait and constant effort. The hunter in France is generally required to withstand eight or ten hours of continuous work and effort without eating, but at a much slower gait. Therefore, the question of the condition of a hunting horse in England and in France is very different.

All summer, you should feed your horse Glauber's salts, one handful in a mash at least once every ten or twelve days. He should have a substantial but gradually increasing feed of 10 to 16 pounds of hay and 10 to 12 quarts of oats every day to begin with, depending upon the temperament of the horse. Give him regular work every day or 
work him two days and let him rest the third day. His work must last at least two hours; at first, one hour at a walk on soft or heavy ground, preferably over ploughed ground, then a moderate but continuous trot over ground that is not too hard, for at least 3 miles; then at least a half hour at a walk. Continue this work for six weeks-that is, till about the 15th of July. Then increase the length of time at the trot and begin to trot in place of walking in the work in the open field, but never push the horse into the rapid gaits. Continue this until about the 15th of August. The muscles of your horse will already begin to grow harder and firmer; they will be stronger and his endurance and wind will be improved. Begin to increase the speed at which he works and then, if he is still too fat, you may give him another purge. A few days later you may increase his oats a little, up to 14 or 16 quarts, depending upon the temperament of the horse. The work is then increased by a gallop over plowed ground, always following a progressive course, beginning with a short and rapid gallop, and ending, on the 15th of September, with a good gallop at hunting speed for 5 or 6 miles. If the horse is still too fat, if the muscles of the neck, loins, and thighs do not stand out well, if he perspires too freely, if the sweat is a white lather and not a colorless fluid, give him two or three gallops under blankets, covering well the parts you wish to lighten. For instance, if the neck is too heavy, too flabby, put on one or two hoods. If, on the contrary, he has too large a belly, put on two or three blankets. Naturally you should always finish at a walk and see that there is a very good grooming when you come in. Put on good flannel bandages after careful hand rubbing of the legs.

By following this course of preparation, your horse should begin to be in condition toward the end of September. He is far from being entirely ready, but he may begin to hunt without much fear of injury. By this time he has started to shed and is beginning to suffer from the action going on inside of him, which takes away part of his strength and exhausts him. Redouble your care by covering him carefully so that the heat may hasten the shedding, and above all give him abundant and substantial feed. Accordingly, from the 15th of September to the 15th of Otober, I recommend a feed of beans every day (2 quarts soaked in three different waters) and put iron, nails, horseshoes, etc., in his drinking water. All this gives him strength to support the work going on inside of him, for it is very important that the shedding and sweating in October should not put him out of condition. If it does, you will not be able to get him back in condition again the rest of the winter, and in January he will be completely run down. Consequently it is from the 20th of September to about the. 15 th of November that you should feed a hunter the most. 
Now, your horse is almost in condition, and may hunt. In the interval between hunts, exercise your horse or have him exercised a little every other day, taking care to take him out for a short time the day after each hunt to observe his condition and the freedom of his movements. If for any reason you do not hunt for a time, you should put your horse through the same work that you did in the month of August, giving him short gallops and work at a walk over plowed ground.

In this manner you keep him fit all winter, giving him good feed and varying it according to his condition and appetite. If he always eats well, continue the oats without overdoing the mashes; the latter should be given only in the evening on coming in from the hunt, and on the next morning feed a cold mash of barley meal. If your horse shows a failing appetite or runs down in condition, give him cooked grain or cooked vegetables.

Thus you reach the month of April and the end of the hunting season. As soon as hunting stops, let your horse rest. Exercise him only at a walk and for his health. Take particular care of the legs and lower his condition by cooling mashes, for a horse can not be kept with impunity on such substantial and heating feed the year around. You might then turn him out in a paddock without grass or with grass that you have had cut short. Give him a mash, a full feed of carrots, and only 6 quarts of oats. Continue this until the 15th of May at least, then stop the carrots and little by little the mashes. Then begin to increase the oats, in order to take up the same work as the preceding year and with the same gradual progress.

During this period of rest, the horse can be given such treatment as the condition of his legs may require.

These are the general instructions for putting a hunter in fit condition for his work.-Count Le Coulteux.

Conditioning for endurance races.-For this training, refer to what has just been said concerning hunters, and to the twenty-ninth question, on training for military races.

The work varies with the length of time available, with the age and condition of the horse and the nature of the race. The only general rules to be repeated here are:

Gradually increase the horse's ration with the work.

Exercise a great deal at a walk in order to develop the muscles.

$53521^{\circ}-10-7$ 
Regulate the walk and trot carefully, and have the horse perfectly calm at these two gaits.

Never use the extended trot.

Accustom the horse not to pull, so that he will not - waste part of his strength fighting the hand.

The morning of the race, massage the tendons; rub both tendons and joints with a fatty substance, such as vaseline; if the race is in the morning, feed little grain, about 1 or 2 quarts.

During the race the periods at a trot should be considerably shorter than during training, in order to avoid winding the horse. Dismount as often as possible, especially going up and down hill. Do not be afraid to water in moderate quantities once or several times on the road; there is no danger if you do not take too fast a gait just after watering.

\section{0}

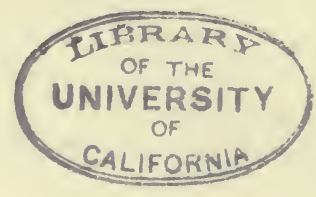





RETURN TO the circulation desk of any

University of California Library

$$
\text { or to the }
$$

NORTHERN REGIONAL LIBRARY FACILITY Bldg. 400, Richmond Field Station University of California Richmond, CA 94804-4698

ALL BOOKS MAY BE RECALLED AFTER 7 DAYS

2-month loans may be renewed by calling

(510) $642-6753$

1-year loans may be recharged by bringing books to NRLF

Renewals and recharges may be made 4 days prior to due date

DUE AS STAMPED BELOW

\section{AUG 111994}


YB 48144

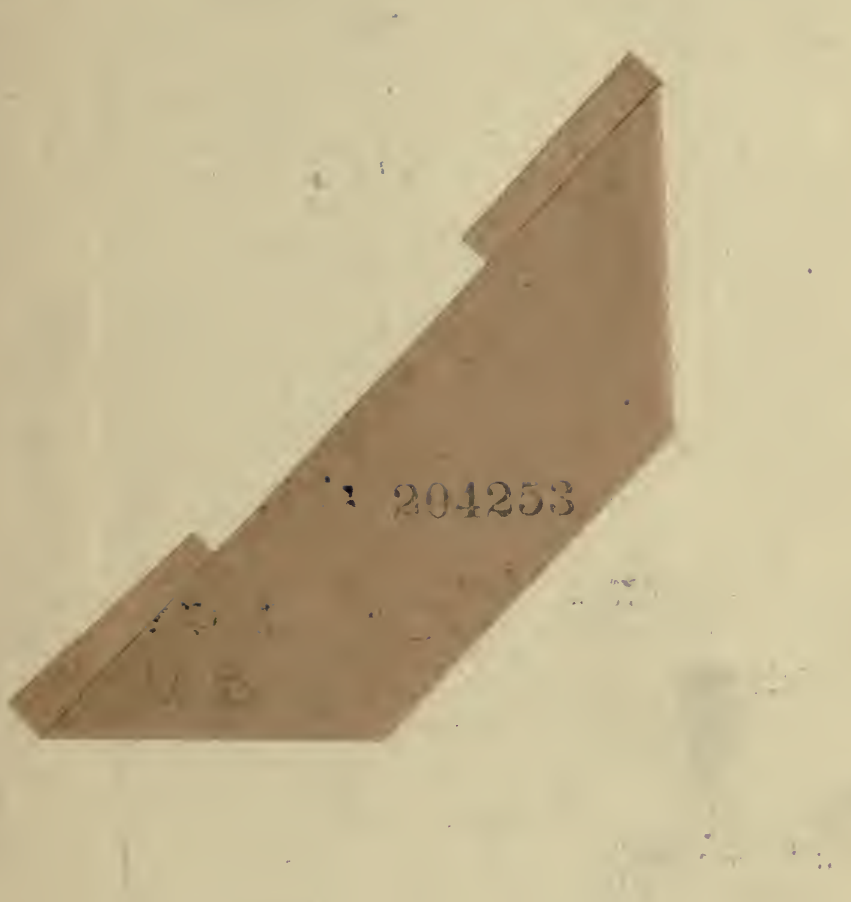


